\title{
Pulmonary Delivery of Engineered Exosomes to Suppress Postoperative Melanoma Lung Metastasis through Preventing Premetastatic Niche Formation
}

\section{Xiaoqing Han}

Changchun Institute of Applied Chemistry, Chinese Academy of Sciences

\section{Luopeng Bi}

Department of Urology, First Hospital of Jilin University

\section{Yunyun Wu}

Changchun University of Technology

\section{Jiao Yan}

Laboratory of Chemical Biology, Changchun Institute of Applied Chemistry, Chinese Academy of

Sciences

\section{Xiaqing Wu}

Laboratory of Chemical Biology, Changchun Institute of Applied Chemistry, Chinese Academy of

Sciences

\section{Runxiao Zheng}

Laboratory of Chemical Biology, Changchun Institute of Applied Chemistry, Chinese Academy of Sciences

yingying Sun

Yanbo Wang

Department of Urology, First Hospital of Jilin University

Haiyuan Zhang ( $\square$ zhangh@ciac.ac.cn )

Laboratory of Chemical Biology, Changchun Institute of Applied Chemistry, Chinese Academy of

Sciences https://orcid.org/0000-0003-4076-1771

\section{Article}

Keywords: Premetastatic niche, Exosome, Pulmonary delivery, Anti-metastasis, IPI549

Posted Date: December 15th, 2021

DOI: https://doi.org/10.21203/rs.3.rs-1133189/v1

License: (c) (i) This work is licensed under a Creative Commons Attribution 4.0 International License.

Read Full License 



\section{Pulmonary Delivery of Engineered Exosomes to Suppress Postoperative}

\section{Melanoma Lung Metastasis through Preventing Premetastatic Niche Formation}

3 Xiaoqing Han ${ }^{1}$, Luopeng $\mathrm{Bi}^{2}$, Yunyun $\mathrm{Wu}^{1}$, Jiao $\mathrm{Yan}^{1}$, Xiaqing $\mathrm{Wu}^{1}$, Runxiao Zheng ${ }^{1}$, Yingying Sun ${ }^{3}$,

4 Yanbo Wang ${ }^{2}$, Haiyuan Zhang ${ }^{1,4 *}$

$5 \quad{ }^{1}$ Laboratory of Chemical Biology, Changchun Institute of Applied Chemistry, Chinese Academy of

6 Sciences, Changchun 130022 (China)

$7 \quad{ }^{2}$ Department of Urology, First Hospital of Jilin University, Changchun, 130021 (China)

$8{ }^{3}$ The Key Laboratory of Molecular Epigenetics of Ministry of Education, Institute of Genetics and

9 Cytology, School of Life Sciences, Northeast Normal University, Changchun 130024 (China)

$10{ }^{4}$ University of Science and Technology of China, Hefei, Anhui 230026 (China).

$11 *$ Corresponding author:

12 Haiyuan Zhang, Laboratory of Chemical Biology, Changchun Institute of Applied Chemistry, Chinese Academy of Sciences, Changchun 130022 (China); University of Science and Technology of China, Hefei, Anhui 230026 (China); E-mail: zhangh@ciac.ac.cn;

\section{Abstract} of PMN formation in distant organs is becoming a promising strategy to suppress metastasis of primary tumor. Based on "organotropic metastasis", melanoma tends to metastasize to lungs, where granulocytic myeloid-derived suppressor cells (G-MDSCs) recruitment in lungs significantly contributes to the PMN formation. Herein, functional exosomes $\left.{ }_{\mathrm{G}} \mathrm{Exo}{ }^{\mathrm{I}}\right)$ were designed to present pulmonary targeting peptide GFE1 on the membrane and load PI3K $\gamma$ inhibitor (IPI549) inside, aiming at suppressing postoperative lung metastasis of melanoma. In postoperative mice model, intravenously injected ${ }_{\mathrm{G}} \mathrm{Exo}^{\mathrm{I}}$ could significantly accumulate in lungs and release IPI549 to block G-MDSCs recruitment through interfering with $\mathrm{CXCLs} / \mathrm{CXCR} 2 / \mathrm{PI} 3 \mathrm{~K} \gamma$ signaling. The increased percentages of $\mathrm{CD}^{+} \mathrm{T}$ cells and $\mathrm{CD} 8^{+} \mathrm{T}$ cells in lungs could transform microenvironment from immunosuppression to immunostimulation, leading to metastasis inhibition. This study suggests an effective anti-metastasis strategy of targeting prevention of PMN formation through specifically blocking G-MDSCs recruitment. 
Key words: Premetastatic niche, Exosome, Pulmonary delivery, Anti-metastasis, IPI549

Introduction

Cancer has become the leading cause of threatening human's health, and various traditional treatments including surgery, radiotherapy and chemotherapy have been applied to treat cancer [1]. However, due to metastasis, the treatment failure and mortality occurs in more than $90 \%$ of individuals with malignant tumors [2-4]. Various anti-metastasis strategies have been developed to improve the treatment of cancer, which mainly focus on the dynamic plasticity of tumor cells, such as the inhibition of migration, adhesion and angiogenesis of tumor cells by drugs[5]. However, as the significant resistance of metastatic tumors to chemotherapy and the limited delivery efficiency of drugs to the tumor metastasis microenvironment, the current treatment of metastasis lacks effectiveness [6]. Moreover, surgery as a necessary step in the treatment of solid cancers, may also facilitate the metastatic process by dissemination of tumor cells during the surgical procedure, local and systemic release of growth factors, and cellular immune suppression[7]. It has been well established that organs of future metastasis are not passive receivers of circulating tumor cells, and before metastasis, the microenvironment of the target organs has been altered, such as marrow derived cell aggregation, continuous inflammation and oxygen free radical increase, which is beneficial for creating a suitable niche for metastatic tumor cells colonization $[8,9]$. This metastasis-favorable microenvironment created in the distant organs by the primary tumor is defined as the premetastatic niche (PMN) [10-12], which is modified by primary tumor-derived factors and extracellular vesicles, bone marrow-derived cells, stromal cells and the cytokines they produce [13]. Therefore, preventing the PMN formation probably is an effective strategy to inhibit the occurrence of metastasis. However, it is challenging to specifically destroy the PMN formation in organs of future metastasis, and only limited approaches have been exploited $[14,15]$.

Granulocytic myeloid-derived suppressor cells (G-MDSCs) are a major population of immature myeloid cells that accumulate in patients with cancer and appear in the early PMN [16-19]. These G-MDSCs are able to induce immunosuppression, increase vascular permeability and promote the colonization and metastatic growth of disseminated tumor cells in PMN [20-22]. The CXCLs/CXCR2 signaling axis plays a vital role in prompting G-MDSCs to enter tissues from bone marrow [23-25]. It has been reported that the primary tumor can recruit CXCR2-positive G-MDSCs by elevating CXCL1 

CXCLs/CXCR2 signaling axis in G-MDSCs is a potential approach to prevent PMN formation and inhibit the metastasis. Phosphoinositide 3-kinase gamma (PI3K $\gamma$ ) pertains to a signal transducing enzyme that plays an important role in CXCLs/CXCR2 signaling axis. Thus, PI3K- $\gamma$ inhibition in G-MDSCs may be effective on blocking G-MDSCs recruitment for PMN elimination. However, since PI3K- $\gamma$ is also a critical determinant of the proportion of neutrophil chemotaxis [27], non-specific PI3K $\gamma$ inhibition would cause the obstacle of the recruitment of neutrophils to non-tumor metastasis organs, resulting in severe immune system defects in the body. Therefore, realization of specific PI3K- $\gamma$ inhibition in G-MDSCs will become a safe and feasible approach for inhibiting PMN formation and further preventing the metastasis.

Clinical observations suggest that most cancers usually can metastasize to specific organs, so called "organotropic metastasis". For examples, melanoma tends to metastasize to lungs; colorectal cancer tends to metastasize to livers; prostate cancers selectively metastasize to bone [28-30]. Such phenotypes offer opportunities to prevent tumor metastasis by specific blocking PMN formation in the organs of future metastasis. Despite the promising anti-metastasis potential of blocking PMN formation, its clinical application is restricted by the lack of organ specificity after systemic administration. Development of biocompatible and organ-targeting drug delivery system will be required. Exosomes naturally secreted by various cell types is membrane-enclosed vesicles with sizes of 30-200 nm [31]. Those exosomes obtained from the patient's own cells have desirable biocompatibility, low immunogenicity and prolonged systemic circulating ability [32-34]. While various exosomes have been used as carriers for anti-tumor metastasis therapy, the affinity of exosomes to mother cells is not sufficient for exosomes to specifically aggregate in one organ of the body [35-37]. Current methods which endow exosomes with the specific targeting ability involve genetic manipulation of the producer cells or chemical conjugation of peptides to the surface of exosomes [32, 38-41]. Therefore, based on above methods, organ-specific targeting exosomes can be obtained with organ-targeting peptides. Furthermore, the engineering organ-targeted exosomes can site-specifically deliver drugs to specific metastasis site, potentially directionally inhibiting the PMN formation in organs of premetastasis. 

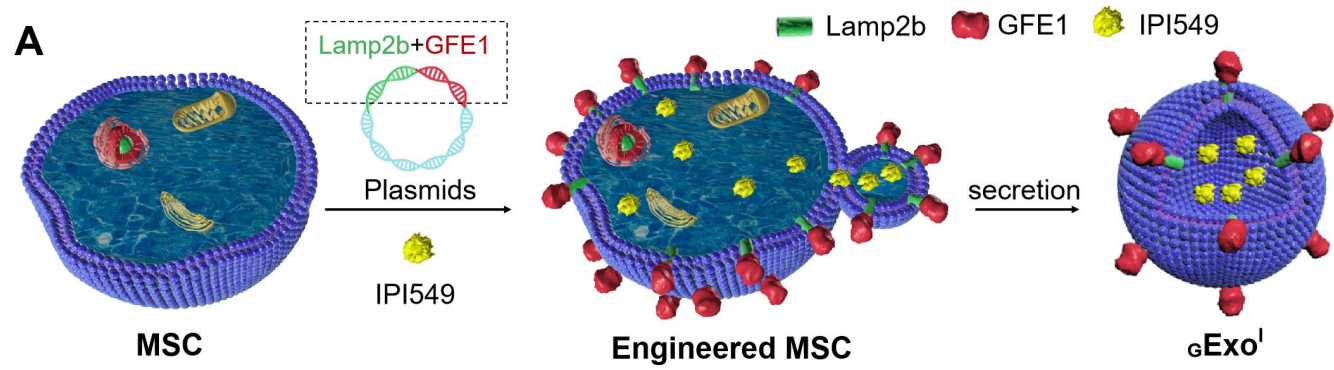

B
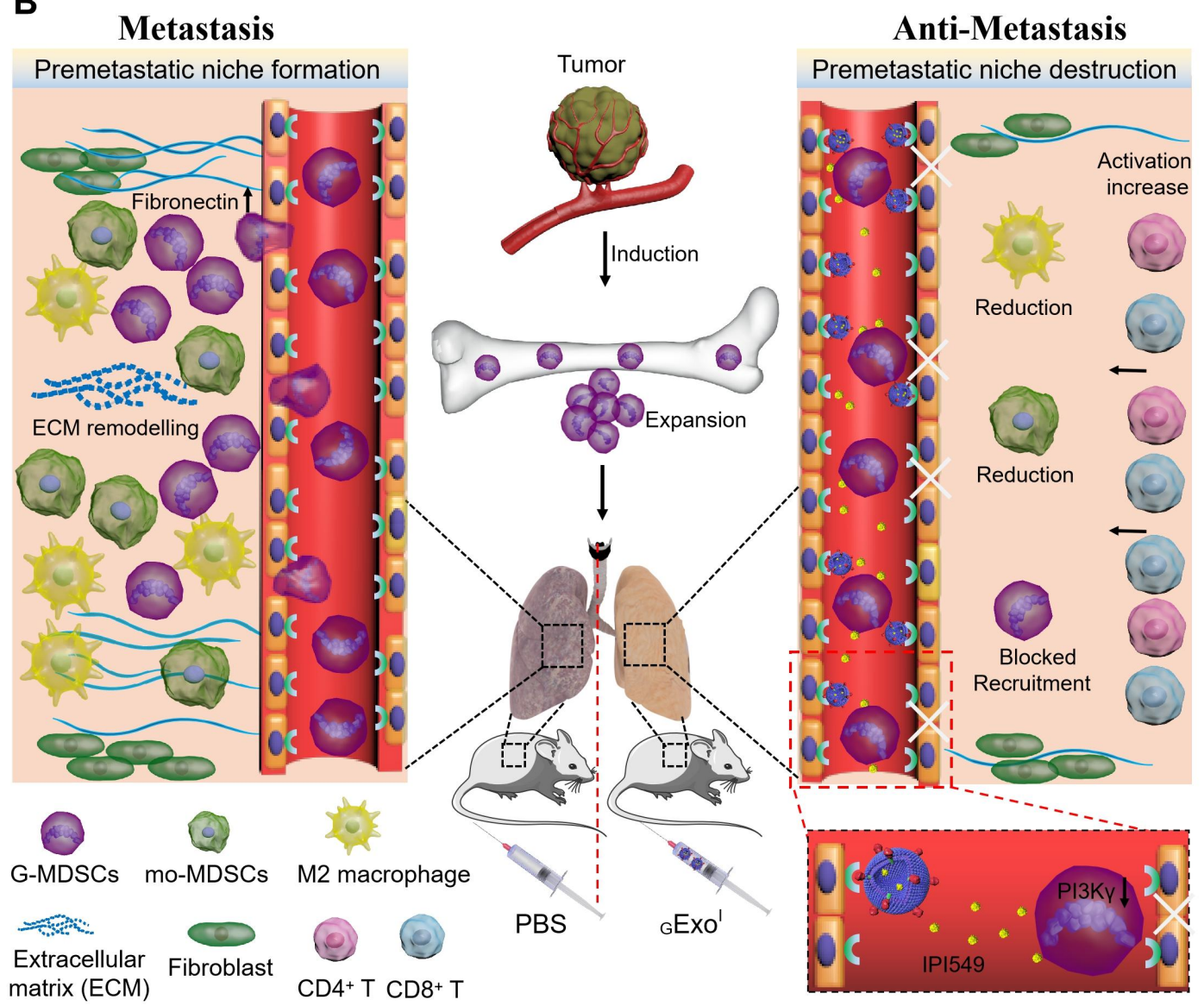

Figure 1 Schematic illustration for anti-tumor metastatic effects of ${ }_{\mathrm{G}} \mathrm{Exo} \mathrm{I}^{\mathrm{I}}$. a Preparation of $\mathrm{G}_{\mathrm{G}} \mathrm{Exo}^{\mathrm{I}}$ from

MSCs that were transfected with the recombinant plasmid encoding Lamp2b-GFE1 fusion protein and incubated with the PI3K $\gamma$ inhibitor, IPI549. b Process of pulmonary delivery of ${ }_{\mathrm{G}} \mathrm{Exo}{ }^{\mathrm{I}}$ through GFE1 binding to the surface of pulmonary vascular endothelial cells and prevention of PMN formation through IPI549-mediated blockage of G-MDSCs recruitment. The decreased percentages of monocytic myeloid-derived suppressor cells (mo-MDSCs) and M2 phenotype macrophage and the increased percentages of $\mathrm{CD}^{+} \mathrm{T}$ cells and $\mathrm{CD} 8^{+} \mathrm{T}$ cells in lungs could transform microenvironment from immunosuppression to immunostimulation, blocking the lung metastasis of melanoma. 
inhibitor (IPI549) to lung of a melanoma mouse model, aiming at preventing the PMN formation and suppressing postoperative lung metastasis of melanoma. Mesenchymal stem cells (MSCs) from the

102 bone marrow of mice were used to produce exosomes with low immunogenicity [42]. The plasmid which expressed lysosome-associated membrane glycoprotein 2b (Lamp2b), an exosomal membrane protein [32], fused with GFE1 (CGFECVRQCPERC) targeting peptide for pulmonary vascular endothelial cells [43] on the extra-exosomal $\mathrm{N}$ terminus of Lamp2b was constructed. Then, the corresponding expression vectors were transfected into MSCs to produce Lamp2b-GFE1 fusion protein, which was exposed on the surface of exosomes. The transfected MSCs were purified and incubated with IPI549 (a PI3K $\gamma$ inhibitor). The GFE-1-positive and IPI549-loaded exosomes ( ${ }_{\mathrm{G}} \mathrm{Exo} \mathrm{I}^{\mathrm{I}}$ ) were purified from cell culture supernatants (Fig.1a). After intravenously injected into a mouse model of melanoma, ${ }_{\mathrm{G}} \mathrm{Exo}^{\mathrm{I}}$ could accumulate at the lung through GFE1 binding to the surface of pulmonary vascular endothelial cells, and gradually release IPI549 to block the G-MDSCs recruitment and preventing the PMN formation, leading to suppression of the lung metastasis of melanoma (Fig. 1b).

113 Collectively, this is the first proof-of-concept attempt to block tumor metastasis based on the tumor metastasis organotropism and the local PMN inhibition, which will serve as a powerful strategy for postoperative metastasis of tumor.

\section{Results and discussion}

\section{Characterization of ${ }_{G} E o^{I}$}

MSCs were isolated from the bone marrow of mice, which were positive for CD29, CD44, and CD105, but negative for CD34 and CD45 (Supplementary Fig. 1). The purity of MSCs in culture was up to $93 \%$. To generate GFE1-positive exosomes, we fused the GFE1 peptide to the extra-exosomal N terminus of murine Lamp2b protein by introducing the pEGFP-C1-GFE1-Lamp2b plasmid into MSCs. The level of GFE1-Lamp2b mRNA was assessed at $24 \mathrm{~h}$ after transfection using reverse transcription polymerase chain reaction (PCR). Relative to untransfected MSCs, the transfected MSCs expressed a high level of GFE1-Lamp2b message RNA (Supplementary Fig. 2). Meanwhile, the transfected MSCs were further incubated with IPI549 for another $24 \mathrm{~h}$. Then, GFE-1 positive and IPI549-loaded exosomes $\left({ }_{\mathrm{G}} \mathrm{Exo}^{\mathrm{I}}\right)$ were achieved from the culture supernatants through ultracentrifugation. The GFE-1 negative exosomes (BExo), GFE-1 positive exosomes ( $\left.{ }_{\mathrm{G}} \mathrm{B} \mathrm{xo}\right)$ and GFE-1 negative but IPI549-loaded exosomes $\left(\mathrm{BExo}^{\mathrm{I}}\right)$ were similarly prepared as controls. Transmission electron microscopy (TEM) and 


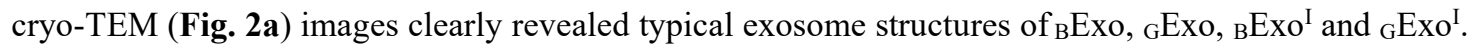

131 Dynamic light scattering (DLS) analysis showed that ${ }_{\mathrm{B}} \mathrm{Exo},{ }_{\mathrm{G}} \mathrm{Exo},{ }_{\mathrm{B}} \mathrm{Exo}^{\mathrm{I}}$ and ${ }_{\mathrm{G}} \mathrm{Exo}^{\mathrm{I}}$ had similar 132 hydrodynamic sizes of $116 \pm 3.3,109 \pm 4.9,110.4 \pm 5.6$ and $114.3 \pm 4.1 \mathrm{~nm}$ respectively (Fig. 2a). Western 133 blot analysis revealed that ${ }_{\mathrm{B}} \mathrm{Exo},{ }_{\mathrm{G}} \mathrm{Exo},{ }_{\mathrm{B}} \mathrm{Exo}^{\mathrm{I}}$ and ${ }_{\mathrm{G}} \mathrm{Exo}^{\mathrm{I}}$ contained the abundant exosome marker proteins, such as TSG101, CD9 and CD63 (Fig. 2b), suggesting that the successful isolation of exosomes from MSCs. To confirm GFE-1 was located on the surface of exosomes, the binding ability of ${ }_{\mathrm{B}} \mathrm{Exo}^{\mathrm{I}}$ and ${ }_{\mathrm{G}} \mathrm{Exo}$ to His-tagged recombinant DPEP1 that is the receptor for the lung-targeting peptide GFE1 was detected by assessing the levels of His-tag in ${ }_{B} \mathrm{Exo}^{\mathrm{I}}$ and ${ }_{\mathrm{G}} \mathrm{Exo}^{\mathrm{I}}$. Western blot analysis showed that ${ }_{\mathrm{G}} \mathrm{Exo}^{\mathrm{I}}$ could strongly bind to DPEP1, but no detectable binding was observed in ${ }_{\mathrm{B}} \mathrm{Exo}^{\mathrm{I}}$ group (Fig. 2c), supporting the existence of GFE1 on the surface of ${ }_{\mathrm{G}} \mathrm{Exo}$. The loading capacities of IPI549 in the ${ }_{\mathrm{G}} \mathrm{Exo}^{\mathrm{I}}$ and ${ }_{\mathrm{B}} \mathrm{Exo}^{\mathrm{I}}$ were determined as 17.79 and $15.59 \%$, respectively, and the IPI549 release profile was investigated by high performance liquid chromatography (HPLC). The results implied that both ${ }_{\mathrm{B}} \mathrm{Exo}^{\mathrm{I}}$ and ${ }_{\mathrm{G}} \mathrm{Exo}^{\mathrm{I}}$ showed similar sustained release profiles, and approximately $83.26 \pm 1.89 \%$ of total IPI549 were slowly released from both exosomes within $24 \mathrm{~h}$. It seems the introduction of GFE1 did not affect the drug release capability of exosomes (Fig. 2d).

a

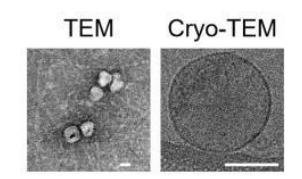

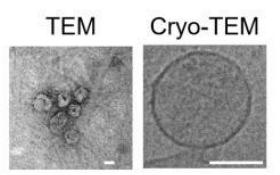
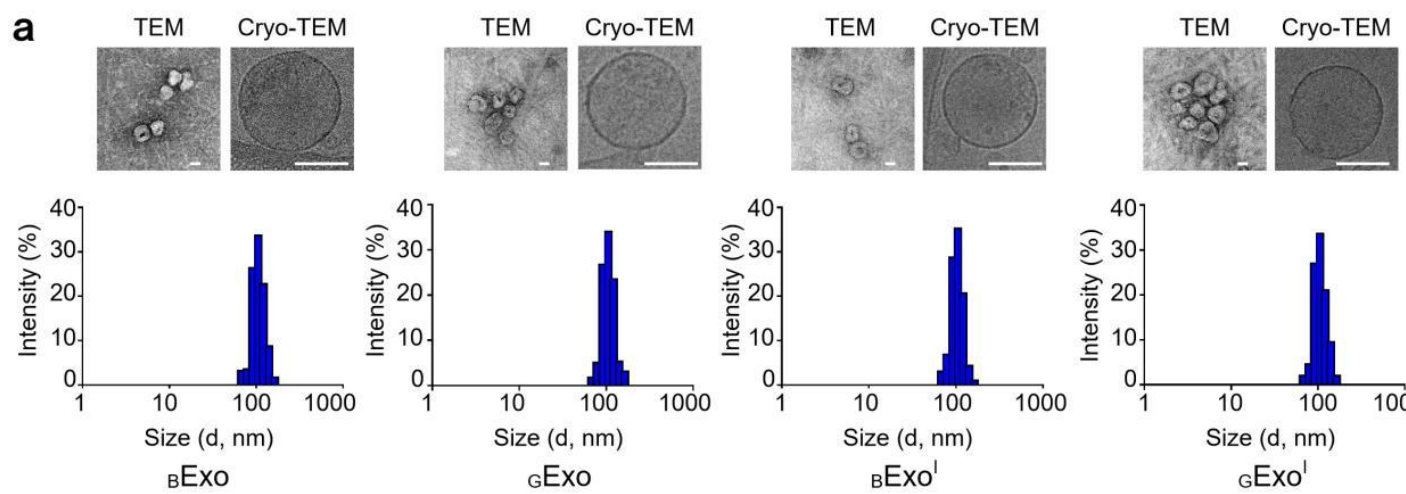

b

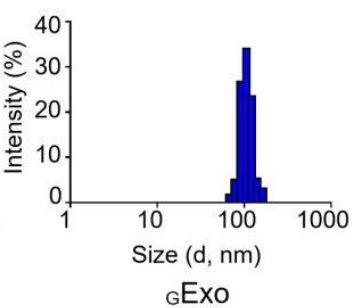

c

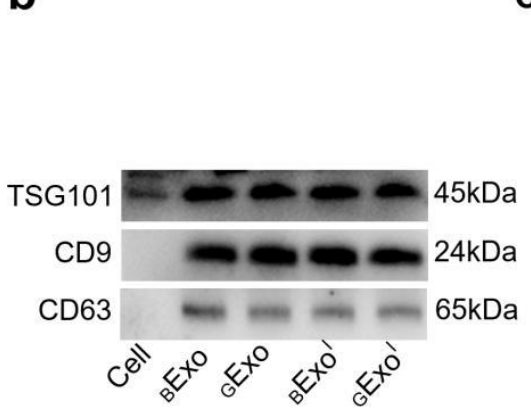

Figure 2. Characterization of exosomes. a TEM and Cryo-TEM images as well as hydrodynamic

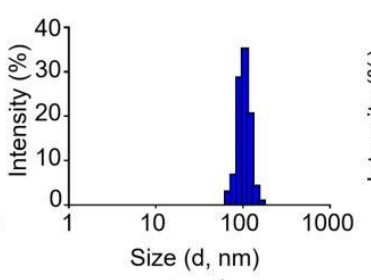

${ }_{B} \mathrm{Exo}^{\prime}$

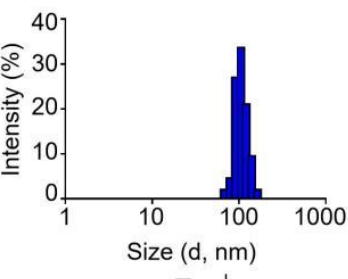

d
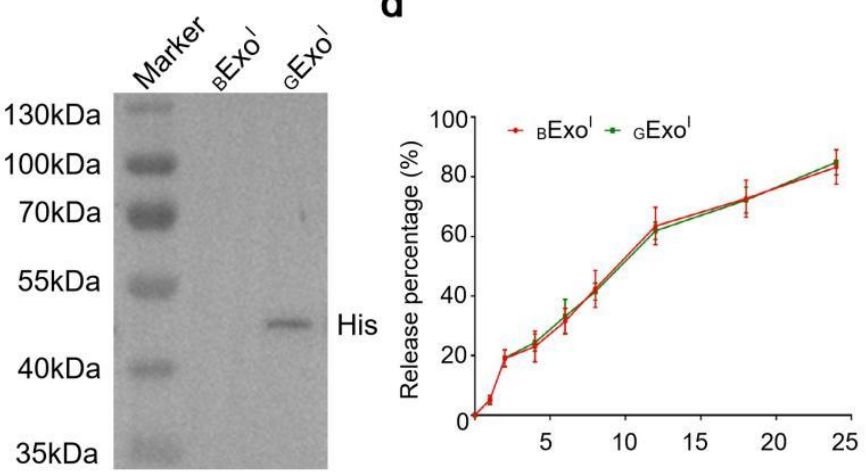

sizes of ${ }_{\mathrm{B}}$ Exo, ${ }_{\mathrm{G}} \mathrm{Exo},{ }_{\mathrm{B}} \mathrm{Exo}^{\mathrm{I}}$ and ${ }_{\mathrm{G}} \mathrm{Exo}^{\mathrm{I}}$. Scale bar, $50 \mathrm{~nm}$. b Western blot analysis of TSG101, CD9 and 
CD63 from IPI549-primed MSCs, ${ }_{\mathrm{B}}$ Exo, ${ }_{\mathrm{G}} \mathrm{Exo},{ }_{\mathrm{B}} \mathrm{Exo}^{\mathrm{I}}$ and ${ }_{\mathrm{G}} \mathrm{Exo}^{\mathrm{I}}$. $\mathbf{c}$ Western blot analysis of ${ }_{\mathrm{B}} \mathrm{Exo}^{\mathrm{I}}$ and ${ }_{\mathrm{G}} \mathrm{Exo}^{\mathrm{I}}$ binding with DPEP1 using an anti-6x His-tag. $\mathbf{d}$ IPI549 release profiles of ${ }_{\mathrm{B}} \mathrm{Exo}^{\mathrm{I}}$ and ${ }_{\mathrm{G}} \mathrm{Exo}^{\mathrm{I}}$ in the phosphate-buffered saline (PBS) over 24 hours. Data are expressed as means \pm SD.

\section{Cellular tropism of ${ }_{\mathrm{G}} \mathrm{Exo}^{\mathrm{I}}$}

The in vitro biocompatibility of ${ }_{\mathrm{G}} \mathrm{Exo}^{\mathrm{I}}$ was assessed by CCK8 assay in murine macrophage cells (RAW 264.7) and human umbilical vein endothelial cells (HUVEC). After $24 \mathrm{~h}$ exposure to different concentrations of ${ }_{\mathrm{B}} \mathrm{Exo}^{\mathrm{I}}$ and ${ }_{\mathrm{G}} \mathrm{Exo}^{\mathrm{I}}$, the viability of cells was found to be weakly affected (Supplementary Fig. 3 and 4). GFE1 peptide has been reported to efficiently target pulmonary vascular [44]. In order to explore the ability of ${ }_{\mathrm{G}} \mathrm{Exo}^{\mathrm{I}}$ targeting to pulmonary vascular, pulmonary vascular endothelial cells (MPVEC) and lung epithelial cells (MLE12) were chosen to be treated with PKH26 (a red fluorescent dye)-labeled ${ }_{\mathrm{B}} \mathrm{Exo}^{\mathrm{I}}$ and ${ }_{\mathrm{G}} \mathrm{Exo}^{\mathrm{I}}$. Cellular fluorescence images showed that ${ }_{\mathrm{G}} \mathrm{Exo} \mathrm{I}^{\mathrm{I}}$ could be efficiently taken into MPVEC rather than MLE12, presenting potent red fluorescence, while ${ }_{\mathrm{B}} \mathrm{Exo}^{\mathrm{I}}$ had low uptake in both MPVEC and MLE12 (Fig. 3a), which reveals the higher affinity of ${ }_{\mathrm{G}} \mathrm{Exo}^{\mathrm{I}}$ compared with ${ }_{\mathrm{B}} \mathrm{Exo}$ toward the pulmonary blood vessels.

The inhibition effect of ${ }_{\mathrm{G}} \mathrm{Exo}^{\mathrm{I}}$ on G-MDSCs migration was investigated in a G-MDSCs/CXCL1 transwell system, where G-MDSCs were cultured in the upper chamber and CXCL1 as chemokine to recruit G-MDSCs was loaded in the lower chamber (Fig. 3b). Various exosomes $\left({ }_{\mathrm{G}} \mathrm{Exo},{ }_{\mathrm{B}} \mathrm{Exo},{ }_{\mathrm{B}} \mathrm{Exo}^{\mathrm{I}}\right.$ and ${ }_{\mathrm{G}} \mathrm{Exo}^{\mathrm{I}}$ ) were incubated with G-MDSCs for $4 \mathrm{~h}$ in the upper chamber. G-MDSCs recruited into the lower chamber were counted by flow cytometry. The results revealed that the numbers of G-MDSCs migration in ${ }_{\mathrm{B}} \mathrm{Exo}^{\mathrm{I}}$ and ${ }_{\mathrm{G}} \mathrm{Exo}^{\mathrm{I}}$ group were less than those in ${ }_{\mathrm{B}} \mathrm{Exo}$ and ${ }_{\mathrm{G}} \mathrm{Exo}$ group (Fig. 3c), and the percentages of migrated G-MDSCs in ${ }_{\mathrm{B}} \mathrm{Exo}^{\mathrm{I}}$ and ${ }_{\mathrm{G}} \mathrm{Exo}^{\mathrm{I}}$ groups were only $8.50 \pm 2.04$ and $7.77 \pm 1.76 \%$ (Supplementary Fig. 5), and the PI3K $\gamma$ expression of G-MDSCs in the upper chamber was down-regulated after both ${ }_{\mathrm{B}} \mathrm{Exo}^{\mathrm{I}}$ and ${ }_{\mathrm{G}} \mathrm{Exo}^{\mathrm{I}}$ treatments (Fig. 3d). All these results suggest IPI549-loaded exosomes can significantly inhibit the migration of G-MDSCs. Furthermore, to investigate the targeted transporting ability of ${ }_{\mathrm{G}} \mathrm{Exo}^{\mathrm{I}}$ to pulmonary vascular endothelial cells, a G-MDSCs/MPVEC/CXCL1 transwell system was established, while G-MDSCs and ${ }_{\mathrm{B}} \mathrm{Exo}^{\mathrm{I}}$ - or ${ }_{\mathrm{G}} \mathrm{Exo}^{\mathrm{I}}$-treated MPVEC were cultured in the upper chamber while CXCL1 was in the lower chamber (Fig. 3e). Because ${ }_{\mathrm{G}} \mathrm{Exo}^{\mathrm{I}}$ could target to MPVEC but ${ }_{\mathrm{B}} \mathrm{Exo}^{\mathrm{I}}$ could not, we hypothesized only ${ }_{\mathrm{G}} \mathrm{Exo}^{\mathrm{I}}$-treated MPVEC carried IPI549 but ${ }_{\mathrm{B}} \mathrm{Exo}$-treated MPVEC did not. Encouragingly, the number of G-MDSCs migration in ${ }_{\mathrm{G}} \mathrm{Exo}^{\mathrm{I}}$-treated 
179 the percentage of migrated G-MDSCs in ${ }_{\mathrm{G}} \mathrm{Exo}$ - -treated MPVEC group decreased to $11.67 \pm 1.25 \%$

180 (Supplementary Fig. 6), which is ascribed to the targeted release of IPI549 of ${ }_{\mathrm{G}} \mathrm{Exo}^{\mathrm{I}}$ in MPVEC.

181 Moreover, the PI3K $\gamma$ expression in G-MDSCs in the upper chamber also was down-regulated in

182 GExo-treated MPVEC group (Fig. 3g). All above results suggest that ${ }_{\mathrm{G}} \mathrm{Exo}^{\mathrm{I}}$ can mediate the targeted 183 delivery of IPI549 to pulmonary vascular endothelial cells and durably inhibit the migration of 184 G-MDSCs by downregulating PI3K $\gamma$.

a

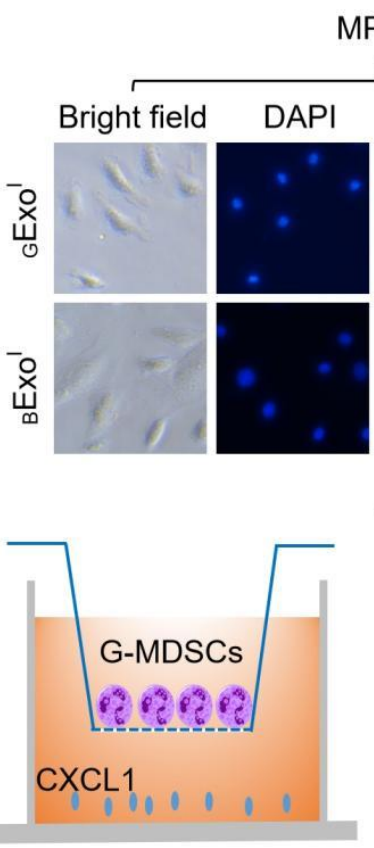

d

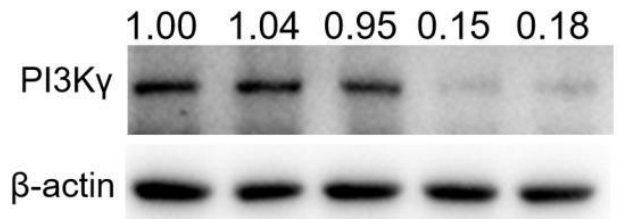

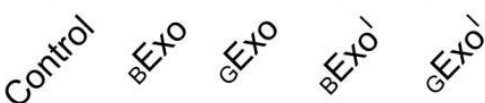

f

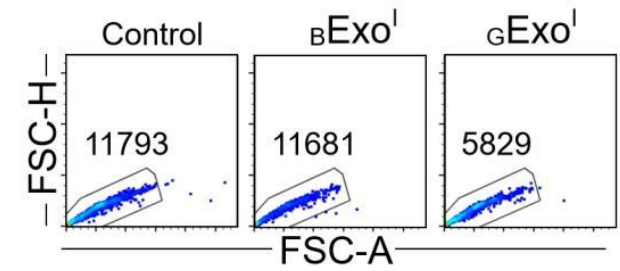

C

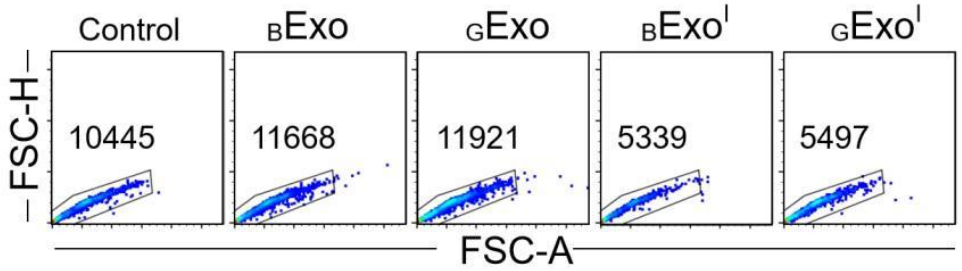

e

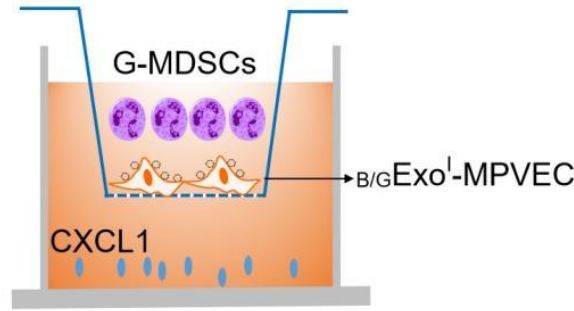

g

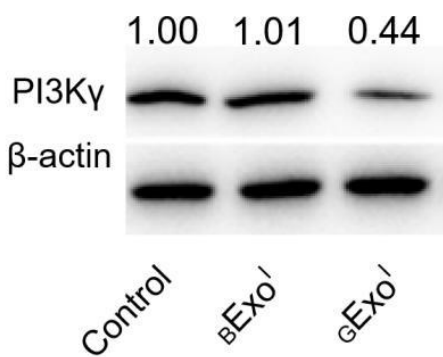

Figure 3. Cellular tropism of $\mathrm{GExo}^{\mathrm{I}}$. a Cellular uptake of ${ }_{\mathrm{G}} \mathrm{Exo}^{\mathrm{I}}$ and ${ }_{\mathrm{B}} \mathrm{Exo}^{\mathrm{I}}$ as assessed by fluorescence 
microscopy. DAPI was used to stain the nuclei (blue). ${ }_{\mathrm{B}}$ Exo and ${ }_{\mathrm{G}} \mathrm{Exo}$ were stained with PKH26 (red). Scale bar, $50 \mu \mathrm{m}$. b Establishment of G-MDSCs/CXCL1 transwell system. $\mathbf{c}$ Migration number of G-MDSCs in G-MDSCs/CXCL1 transwell system as assessed by flow cytometry. d Western blot analysis of PI3K $\gamma$ expression in G-MDSCs of G-MDSCs/CXCL1 transwell system. e Establishment of G-MDSCs/MPVEC/CXCL1 transwell system. $\mathbf{f}$ Migration number of G-MDSCs in G-MDSCs/CXCL1 transwell system as assessed by flow cytometry. $\mathbf{g}$ Western blot analysis of PI3K $\gamma$ expression in G-MDSCs in G-MDSCs/MPVEC/CXCL1 transwell system. Data are expressed as means $\pm \mathrm{SD}$.

\section{Enhanced pulmonary targeting ability and bioavailability of ${ }_{G} E 0^{I}$}

Encouraged by above in vitro results, the in vivo biodistribution of ${ }_{\mathrm{G}} \mathrm{Exo}^{\mathrm{I}}$ was then taken further investigation. The pKH26-labeled ${ }_{\mathrm{B}} \mathrm{Exo}^{\mathrm{I}}$ or ${ }_{\mathrm{G}} \mathrm{Exo}^{\mathrm{I}}$ was injected intravenously to healthy $\mathrm{C} 57 \mathrm{BL} / 6$ mice, and the fluorescence images of the major organs showed that ${ }_{\mathrm{B}} \mathrm{Exo}^{\mathrm{I}}$ and ${ }_{\mathrm{G}} \mathrm{Exo}^{\mathrm{I}}$ mainly distributed in the liver, kidney and lung, among which ${ }_{\mathrm{G}} \mathrm{Exo}^{\mathrm{I}}$ had the highest accumulation in the lung while ${ }_{\mathrm{B}} \mathrm{Exo}^{\mathrm{I}}$ had the highest one in the liver (Fig. 4a and b). This result reveals the excellent pulmonary targeting ability of ${ }_{\mathrm{G}} \mathrm{Exo}$, which is attributed to GFE1 peptide on the surface of ${ }_{\mathrm{G}} \mathrm{Exo}$. To further determine the detailed distribution of ${ }_{\mathrm{B}} \mathrm{Exo}^{\mathrm{I}}$ and ${ }_{\mathrm{G}} \mathrm{Exo}^{\mathrm{I}}$ in the lung tissue, the lung slices were stained with FITC-CD31, a vascular endothelial cell marker. Fluorescence microscopy image showed that the red fluorescence of pKH26-labeled ${ }_{\mathrm{G}} \mathrm{Exo}^{\mathrm{I}}$ was bound to the pulmonary vasculature, however, only a few of pKH26-labeled ${ }_{\mathrm{B}} \mathrm{Exo}{ }^{\mathrm{I}}$ distributed irregularly throughout the lung slice (Fig. $\left.4 \mathbf{c}\right)$. Next, the biodistributions of IPI549 in different organs of mice was quantitatively analyzed by HPLC. Treatments with ${ }_{B} E_{x o^{I}}$ or ${ }_{G} E o^{I}$ could increase the accumulation of IPI549 in the liver(Supplementary Fig. 7), kidney (Supplementary Fig. 8) and lungs (Fig. 4d ) of mice as compared with treatment with free IPI549, and more importantly, ${ }_{\mathrm{G}} \mathrm{Exo}^{\mathrm{I}}$ compared with ${ }_{\mathrm{B}} \mathrm{Exo}^{\mathrm{I}}$ could more significantly increase the accumulation of IPI549 in the lung. This result demonstrates ${ }_{\mathrm{G}} \mathrm{Exo}^{\mathrm{I}}$ can enhance the accumulation of IPI549 in the pulmonary vasculature by binding to vascular endothelial cells in the lung. To evaluate the pharmacokinetic profile of IPI549, the time-dependent IPI549 plasma concentration of mice injected with free IPI549 or exosomes ${ }_{\left(\mathrm{B} E x 0^{\mathrm{I}}\right.}$ and ${ }_{\mathrm{G}} \mathrm{Exo} \mathrm{I}^{\mathrm{I}}$ ) was investigated by HPLC. Fig. 4e showed that the maximum IPI549 plasma concentration (C max) of mice with free IPI549 treatment peaked at 20 min post-injection, which was $0.38 \mu \mathrm{gL}^{-1}$, and then decreased rapidly. The $\mathrm{C}$ max of mice with ${ }_{\mathrm{BExo}}{ }^{\mathrm{I}}$ or ${ }_{\mathrm{G}} \mathrm{Exo}^{\mathrm{I}}$ treatment peaked at $2 \mathrm{~h}$ post-injection and was improved to $0.72 \mu \mathrm{g} \mathrm{mL}-1$ (for ${ }_{\mathrm{G}} \mathrm{Exo}^{\mathrm{I}}$ ) or $0.78 \mu \mathrm{g} \mathrm{mL} \mathrm{L}^{-1}$ (for ${ }_{\mathrm{B}} \mathrm{Exo}^{\mathrm{I}}$ ). Compared 
217 with free IPI549, both ${ }_{\mathrm{G}} \mathrm{Exo}^{\mathrm{I}}$ and ${ }_{\mathrm{B}} \mathrm{Exo}^{\mathrm{I}}$ also contributed to the higher bioavailability and slower 218 metabolism rate.

a

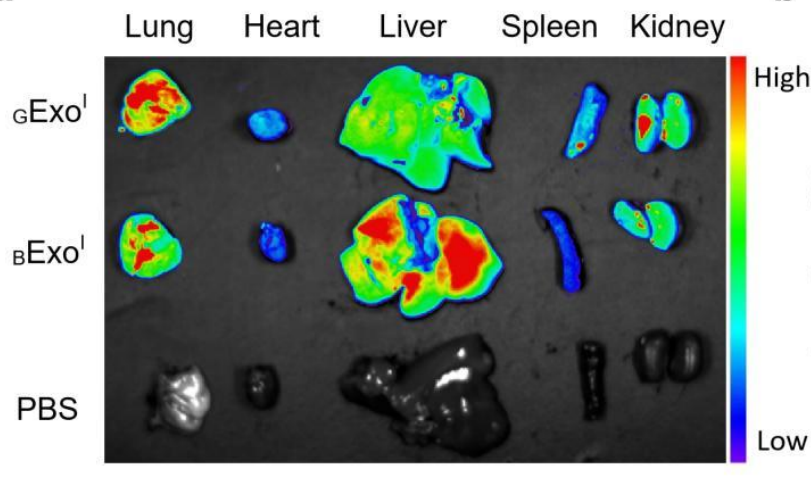

C
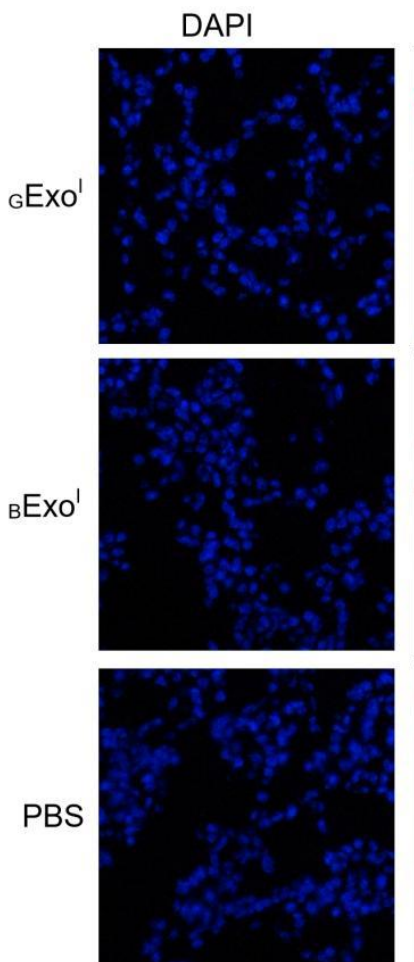

d
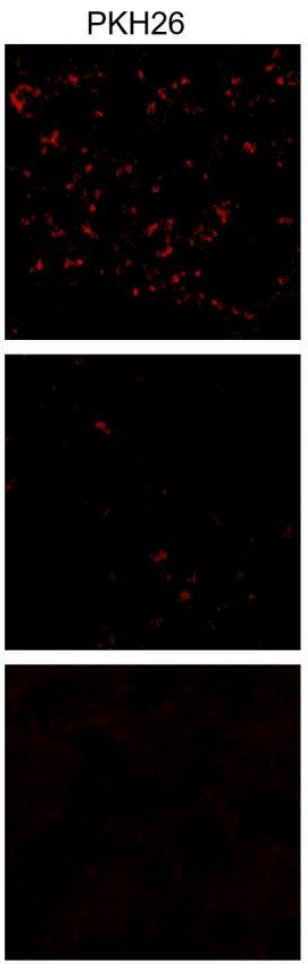

e

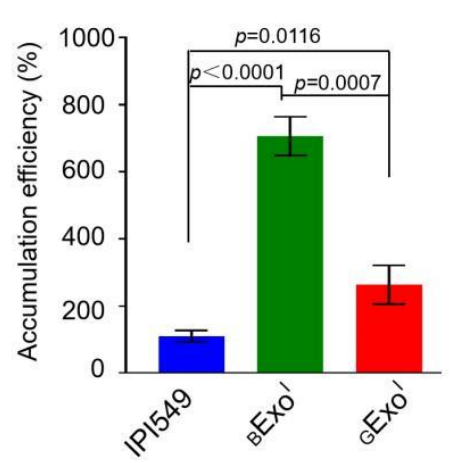

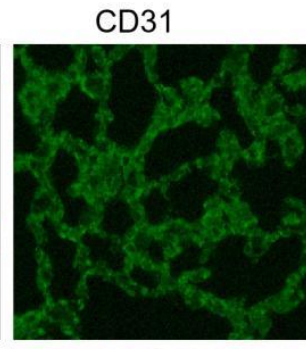
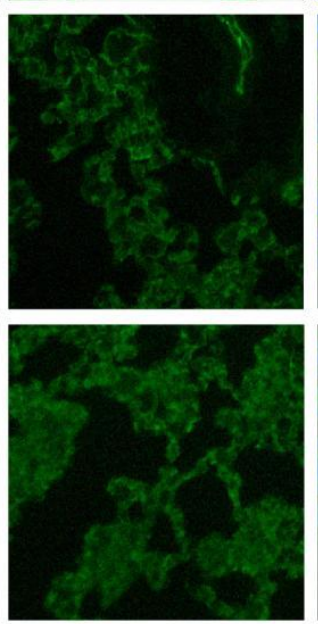

b
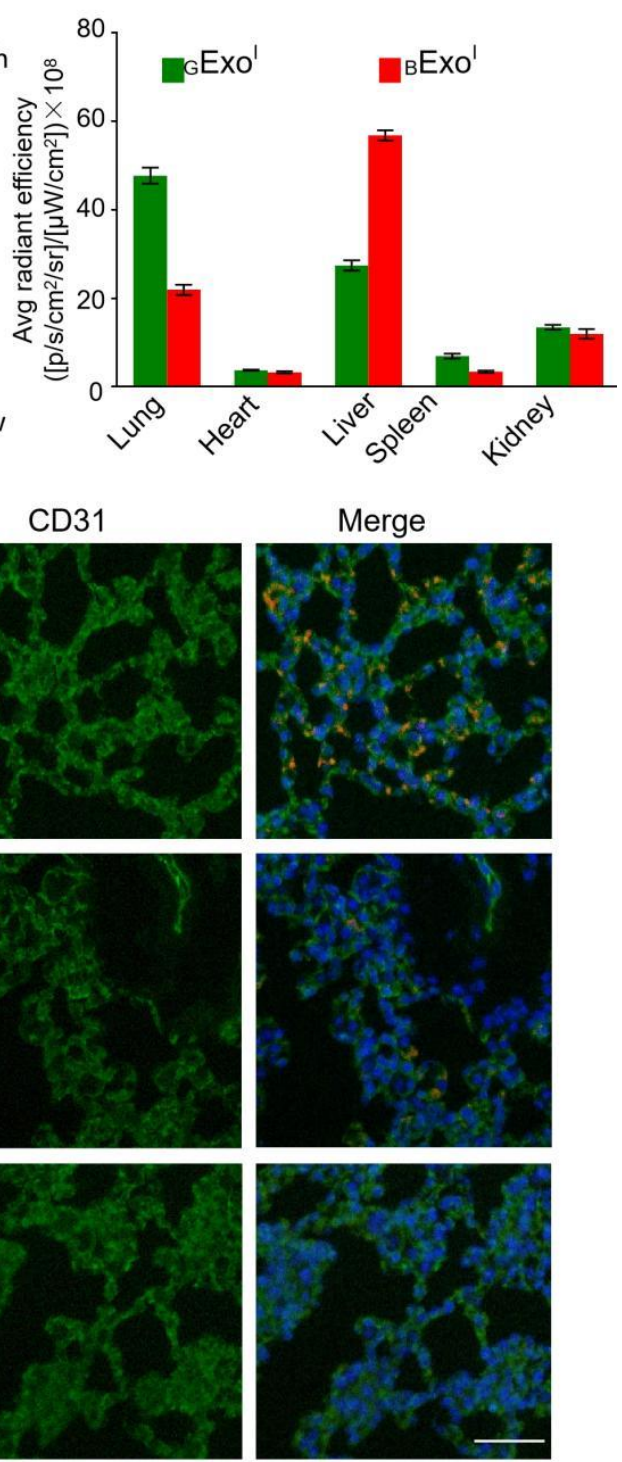

e

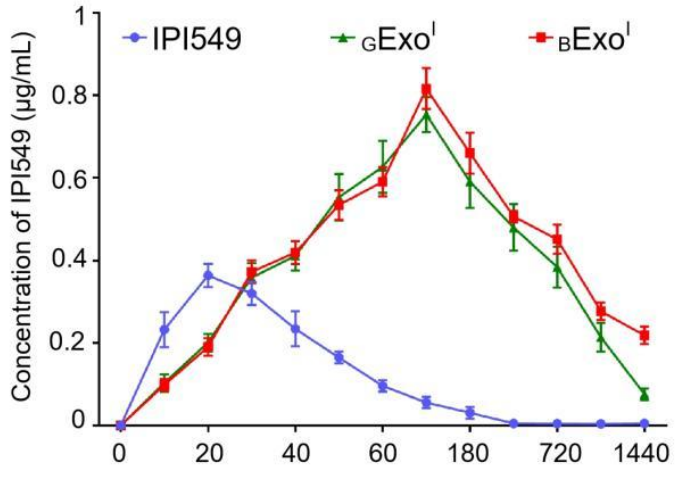

220 Figure 4. Pulmonary targeting of ${ }_{G} \mathbf{E x o}^{\mathbf{I}}$. a Ex vivo fluorescence images of the major organs (heart,

221 liver, spleen, lung, and kidney) from mice at $24 \mathrm{~h}$ postinjection with PBS, $\mathrm{PKH} 26-$ labeled ${ }_{\mathrm{B}} \mathrm{Exo}^{\mathrm{I}}$ or 
${ }_{\mathrm{G}} \mathrm{Exo}^{\mathrm{I}}$, respectively. b Semi-quantitation of fluorescence intensity of major organs. c Immunofluorescent images of lung tissues stained by the vascular endothelial cells marker CD31 (green). Scale bar, $100 \mu \mathrm{m}$. d Tissue distribution of IPI549 in the lung of mice treated as described in Figure 4a. e Plasma concentration-time curve of IPI549 in mice plasma after single intravenous injection of free IPI549, ${ }_{\mathrm{B}} \mathrm{Exo}^{\mathrm{I}}$ or ${ }_{\mathrm{G}} \mathrm{Exo}^{\mathrm{I}}$ (equivalent to the concentration of $0.2 \mathrm{mg}$ IPI549/kg mouse). Data are expressed as means $\pm \mathrm{SD} . \mathrm{n}=5$ biologically independent animals per group.

\section{Therapeutic efficacy of ${ }_{\mathrm{G}} \mathbf{E x o}^{\mathrm{I}}$ to suppress postoperative metastasis of melanoma}

The primary tumor tissue can induce the spontaneous development of PMN, and tumor metastasis will occur once the PMN is formed, even if the tumor in situ is surgically removed [10]. To evaluate the inhibitory efficacy of ${ }_{\mathrm{G}} \mathrm{Exo}^{\mathrm{I}}$ against PMN formation in the lung, B16/F10 cells-derived tumor conditioned medium (TCM) stimulating mice model was established. The TCM using as tumor secretions was intravenously injected into normal C57BL/6 mice, and free IPI549, ${ }_{\mathrm{B}} \mathrm{Exo}^{\mathrm{I}}$ or ${ }_{\mathrm{G}} \mathrm{Exo}^{\mathrm{I}}$ was injected intravenously at the same time, followed by intravenous injection of B16/F10 cells (Fig. 5a). The PMN characteristic gene expression in lungs, including Bv8, S100a8, S100a9, and MMP9, which are reported to promote tumor cell invasion, migration, and colonization in the metastatic site [45], were assessed by real-time PCR. The result showed the treatment with TCM alone significantly increased the expression of Bv8, S100a8, S100a9, and MMP9 in the lung than that of normal mice (Supplementary Fig. 9). However, additional treatment with free IPI549, ${ }_{\mathrm{B}} \mathrm{Exo}^{\mathrm{I}}$ or ${ }_{\mathrm{G}} \mathrm{Exo}^{\mathrm{I}}$ decreased their expression, where ${ }_{\mathrm{G}} \mathrm{Exo}^{\mathrm{I}}$ exhibited the most potent performance, suggesting ${ }_{\mathrm{G}} \mathrm{Exo} \mathrm{I}^{\mathrm{I}}$ can effectively inhibit lung PMN establishment. Furthermore, the metastatic nodules in the lung of mice were counted. Only TCM-treated mice showed the most metastatic nodules, accelerating the metastasis, but the further treatment with IPI549, ${ }_{\mathrm{B}} \mathrm{Exo}^{\mathrm{I}}$ or ${ }_{\mathrm{G}} \mathrm{Exo}^{\mathrm{I}}$ induced the reduced metastatic nodules, showing inhibited metastasis (Fig. 5b and 5c). Importantly, ${ }_{\mathrm{G}} \mathrm{Exo}^{\mathrm{I}}$ triggered the least metastatic nodules, exhibiting the best inhibitory activity against metastasis. All above results indicate that ${ }_{\mathrm{G}} \mathrm{Exo}^{\mathrm{I}}$ can significantly inhibit tumor metastasis by blocking PMN formation in the lung. 
a Injection with PBS/IPI549/BExo///Exo'

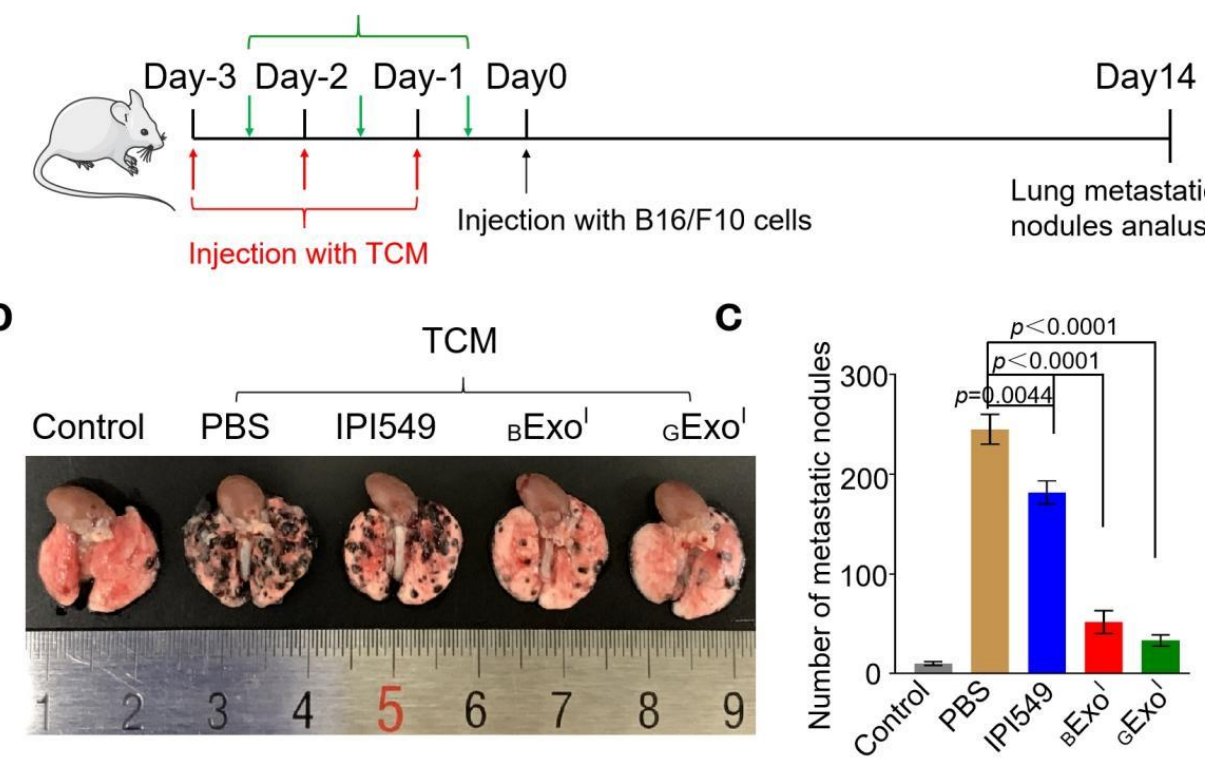

d

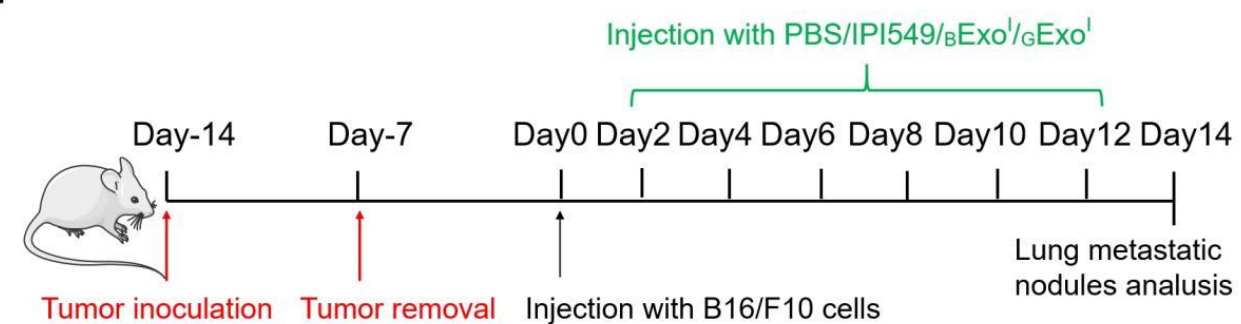

e
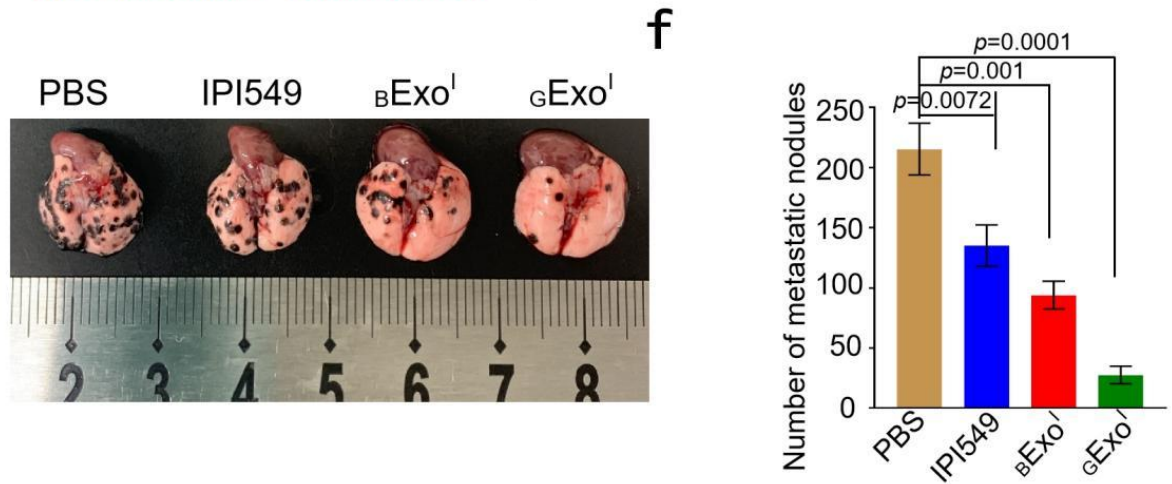

g

PBS

IPI549
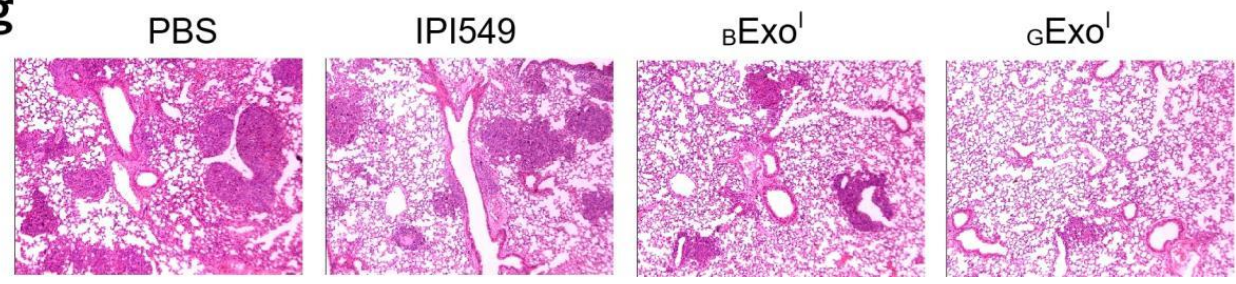

$f$ nodules analusis

249 Figure 5. Suppressed metastasis by ${ }_{\mathbf{G}} \mathbf{E x o}^{\mathrm{I}}$. a Treatment schedule and timeline for TCM stimulation,

250 treatments with various drug formulations, and lung metastasis evaluation. Days were recounted from

251 day 0 after all TCM stimulations and treatments. b The metastatic nodules in the lungs of control mice

252 without injection with TCM and mice injected with TCM + PBS, TCM + IPI549, TCM $+{ }_{\mathrm{B}} \mathrm{Exo}$, or 
$\mathrm{TCM}+{ }_{\mathrm{G}} \mathrm{Exo}$. All mice were sacrificed at 2 weeks after a tail vein injection with $\mathrm{B} 16 \mathrm{~F} 10$ cells. The black point represented visible metastatic nodules in the lung. $\mathbf{c}$ Average number of macroscopic lung metastatic nodules in mice treated as in Figure 5B. d Schematic illustration of postoperative lung metastasis models and therapies. e Images of the lung tissue from postoperative lung metastasis mice treated with PBS, IPI549, ${ }_{\mathrm{BExo}}{ }^{\mathrm{I}}$ or ${ }_{\mathrm{G}} \mathrm{Exo}^{\mathrm{I}}$. f Average number of macroscopic lung metastatic nodules in mice treated as described in Figure 5E. g H\&E-stained tissue sections of lung excised at the end of treatments. Scale bar, $100 \mu \mathrm{m}$. For e-g, mice whose subcutaneous tumors $\left(100 \mathrm{~mm}^{3}\right)$ were completely excised were intravenously injected with B16/F10 cells at 7 days post-surgery. PBS, free IPI549, ${ }_{\mathrm{B}} \mathrm{Exo}{ }^{\mathrm{I}}$ or ${ }_{\mathrm{G}} \mathrm{Exo}^{\mathrm{I}}$ was injected intravenously to the mice every two days after injection with B16/F10 cells. All mice were sacrificed at 2 weeks after intravenous injection with B16F10 cells. Data are expressed as

To finally determine whether ${ }_{\mathrm{G}} \mathrm{Exo} \mathrm{I}^{\mathrm{I}}$ can prevent the postoperative tumor metastasis, the postoperative lung metastasis model was generated in C57BL/6 mice. B16/F10 cells were first subcutaneously injected in C57BL/6 mice. When the tumor volume reached about $100 \mathrm{~mm}^{3}$, the tumor was completely excised, followed by intravenous injection of B16/F10 cells at 7 days post-surgery. PBS, free IPI549 or the exosomes $\left({ }_{\mathrm{B}} \mathrm{Exo}^{\mathrm{I}}\right.$ and $\left.{ }_{\mathrm{G}} \mathrm{Exo}^{\mathrm{I}}\right)$ were injected intravenously to the mice every two days after injection of B16/F10 cells (Fig. 5d). Compared to the mice treated with free IPI549, the number of macroscopic metastatic nodules of both exosomes-treated mice was dramatically decreased, where ${ }_{\mathrm{G}} \mathrm{Exo}^{\mathrm{I}}$ still showed more significant metastases inhibition than ${ }_{\mathrm{B}} \mathrm{Exo}^{\mathrm{I}}(\mathbf{F i g} . \mathbf{5 e}$ and 5f). From the hematoxylin-eosin (H\&E) staining of the lung metastatic lesions (Fig. 5g), metastatic nodules and inflammation could be distinctly detected in PBS-treated mice. While treatments with free IPI549 or ${ }_{\mathrm{B} E x 0^{\mathrm{I}}}$ could decrease the nodules and inflammation in the lung, there was barely the nodules and inflammation in the lung of ${ }_{\mathrm{G}} \mathrm{Exo}^{\mathrm{I}}$-treated mice, indicating the remarkable anti-metastatic efficacy of ${ }_{\mathrm{G}} \mathrm{Exo}$.

\section{Inhibited G-MDSCs accumulation in the lung by ${ }_{G} E_{x 0} \mathrm{I}$ to prevent PMN formation}

It has been demonstrated that G-MDSCs play a vital role in promoting metastases in tumor-bearing mice, and their accumulation in premetastatic organs is a complex process that is regulated mainly by CXCLs factors (CXCL1, CXCL2, CXCL5, and CXCL8)[23]. Because of the wide range of factors, it is difficult to achieve anti-tumor metastasis by simply inhibiting the expression of a certain factor [46]. 
Here, we first design an anti-accumulation strategy to inhibit the chemotactic migration of G-MDSCs into the lung by blocking the CXCLs/CXCR2/PI3K $\gamma$ signaling of G-MDSCs. To investigate the influence of ${ }_{\mathrm{G}} \mathrm{Exo}^{\mathrm{I}}$ on G-MDSCs recruitment before PMN formation, the percentage of G-MDSCs $\left(\mathrm{CD} 11 \mathrm{~b}^{+} \mathrm{Ly} 6 \mathrm{G}^{+}\right)$in the lung of the postoperative lung metastasis mice model was analyzed by flow cytometry. Fig. 6a and Supplementary Fig. 10 show that IPI549 and ${ }_{B} E x 0^{I}$ could reduce the percentage of G-MDSCs in premetastatic lungs, but ${ }_{\mathrm{G}} \mathrm{Exo}^{\mathrm{I}}$ even decreased the percentage close to the normal level of healthy mice, which is because on the one hand ${ }_{\mathrm{G}} \mathrm{Exo}^{\mathrm{I}}$ has a longer circulation time than IPI549, capable of more effectively blocking the chemotactic migration of G-MDSCs, and on the other hand, ${ }_{\mathrm{G}} \mathrm{Exo}^{\mathrm{I}}$ has a higher drug delivery efficiency than ${ }_{\mathrm{B}} \mathrm{Exo}^{\mathrm{I}}$, thus releasing the stronger anti-recruitment ability. Moreover, the expression of PI3K $\gamma$ in G-MDSCs from premetastatic lungs of mice with different treatments was observed to show the same trend as the percentage of G-MDSCs did (Fig. 6b).

G-MDSCs can suppress the immunity by perturbing both innate and adaptive immune responses, such as promoting the generation of monocytic myeloid-derived suppressor cells (mo-MDSCs), skewing macrophage towards an M2 phenotype, and blocking the activation and proliferation of $\mathrm{CD} 8^{+}$ $\mathrm{T}$ cells $[47,48]$. Then, the impact of ${ }_{\mathrm{G}} \mathrm{Exo}^{\mathrm{I}}$ on the function of G-MDSCs was further assessed. The percentages of the major immune cells in the lung tissues were detected by flow cytometry in the lung of the postoperative lung metastasis mice model. The percentages of mo-MDSCs $\left(\mathrm{CD} 11 \mathrm{~b}^{+} \mathrm{Ly} 6 \mathrm{C}^{+}\right)$and M2 macrophages $\left(\mathrm{F} 4 / 80^{+} \mathrm{CD} 206^{+}\right)$in the lungs of the ${ }_{\mathrm{G}} \mathrm{Exo}{ }^{\mathrm{I}}$-treated mice decreased most significantly, which probably is because the decreased G-MDSCs could cause the decrease of mo-MDSCs generation and impairment of macrophage polarization towards an M2 phenotype (Fig. 6c and Supplementary

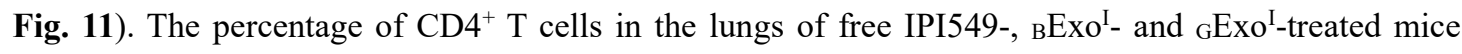
were increased, compared with that of PBS-treated mice (Fig. 6d and Supplementary Fig. 12), indicating that the reduction of G-MDSCs can achieve the remodeling of acquired immunity. Moreover, the percentage of $\mathrm{CD} 8^{+} \mathrm{T}$ cells in the lungs of the ${ }_{\mathrm{G}} \mathrm{Exo}^{\mathrm{I}}$-treated mice increased most significantly (Fig. 6d and Supplementary Fig. 13). Based on the above results, the composition ratio of various immune cells in the premetastatic lung was changed by the reduction of G-MDSCs. IFN $\gamma$ coordinates multiple protective functions to enhance the immune response to infection and cancer [49] and IL-10 is a pleiotropic anti-inflammatory cytokine that induces immunosuppression and assists in escape from tumor immune surveillance [50]. The lung homogenate of postoperative lung metastasis mice model 
314 immunosorbent assay (ELISA). As shown in Figure 6e and f ${ }_{\mathrm{G}} \mathrm{Exo}^{\mathrm{I}}$ could induce the highest level of 315 IFN $\gamma$ among the four treatment groups and the level of IL10 close to that in healthy mice, due to the 316 targeted IPI549 delivery ability of ${ }_{\mathrm{G}} \mathrm{Exo}^{\mathrm{I}}$. Taken all together, the reduction of G-MDSCs by ${ }_{\mathrm{G}} \mathrm{Exo}^{\mathrm{I}} \mathrm{can}$ create an immune activated microenvironment in the premetastatic lung.

a

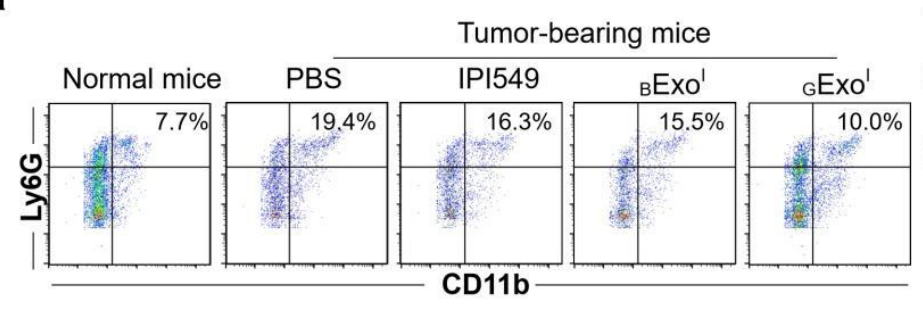

C
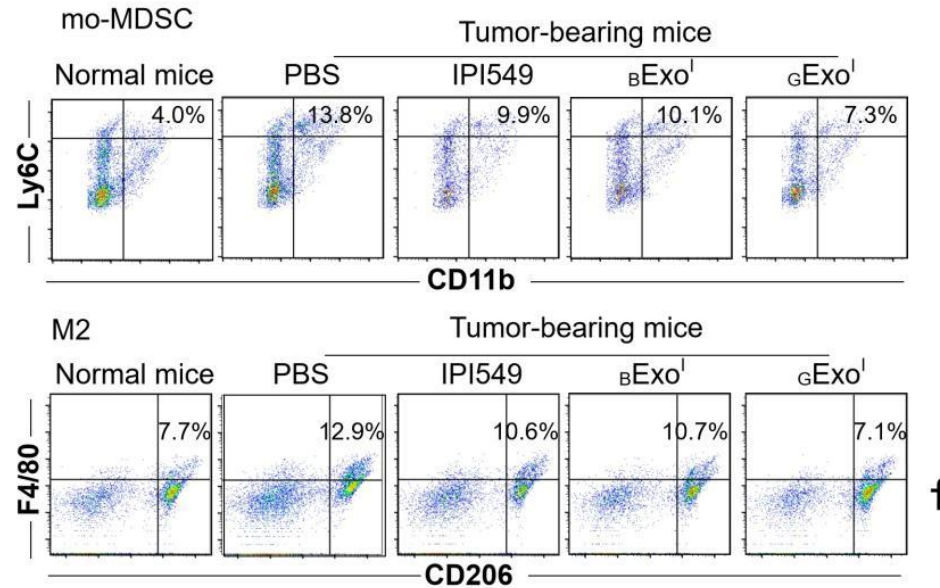

d

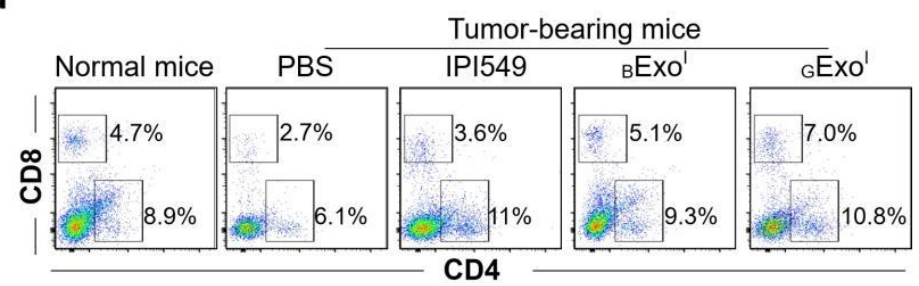

b

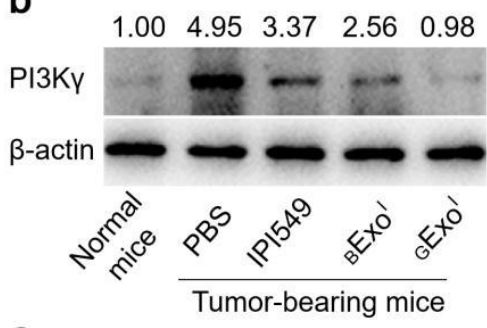

e

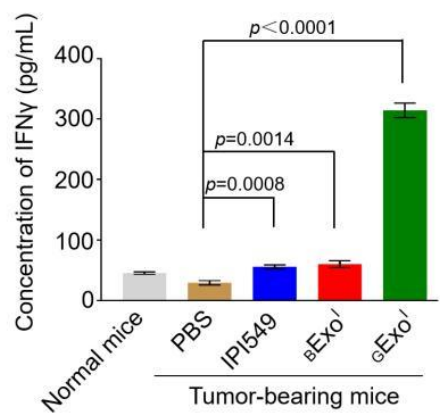

f

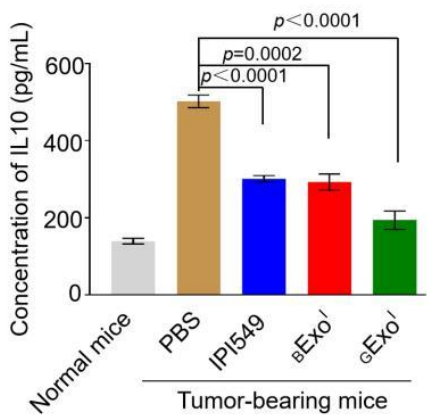

Figure 6. Prevented PMN formation by ${ }_{G} \operatorname{Exo}^{\mathrm{I}}$ in the lung of postoperative lung metastasis mice. a Flow cytometry analysis of the percentage of G-MDSCs. b Western blot analysis of the PI3K $\gamma$ expression in G-MDSCs. c Flow cytometry analysis of the percentages of mo-MDSCs and M2 macrophages. d Flow cytometry analysis of the percentage of $\mathrm{CD} 4^{+} \mathrm{T}$ cells and $\mathrm{CD} 8^{+} \mathrm{T}$ cells. e, $\mathbf{f}$ ELISA analysis of the level of IFN $\gamma$ e and IL10 f. For Figure 6a-f, mice whose subcutaneous tumors $\left(100 \mathrm{~mm}^{3}\right)$ were completely excised were intravenously injected with B16/F10 cells at 7 days post-surgery. PBS, free IPI549, ${ }_{\mathrm{B}} \mathrm{Exo}^{\mathrm{I}}$ and ${ }_{\mathrm{G}} \mathrm{Exo}^{\mathrm{I}}$ were injected intravenously to the mice every two days after injection with B16/F10 cells. All mice were sacrificed at 2 weeks after intravenous injection with 
B16F10 cells. And the lungs of the mice were used to prepare single-cell suspensions and lung homogenates for flow cytometry and ELISA analysis. Data are expressed as means \pm SD. $n=5$ biologically independent animals per group.

\section{In vivo biocompatibility of ${ }_{\mathrm{G}} \mathrm{Exo}^{\mathrm{I}}$}

In vivo biocompatibility of ${ }_{\mathrm{G}} \mathrm{Exo}^{\mathrm{I}}$ was assessed by histological examination of major organs and blood chemistry tests. No noticeable damage was found in H\&E stained tissue sections of major organs (heart, liver, spleen, lung and kidney) of mice at the end of treatments with IPI549, ${ }_{\mathrm{B}} \mathrm{Exo}^{\mathrm{I}}$ or $_{\mathrm{G}} \mathrm{Exo}^{\mathrm{I}}$ (Fig. 7a). Serum biochemical indices of aspartate aminotransferase (AST), alanine aminotransferase (ALT), creatinine (CREA) and blood urea nitrogen $(\mathrm{BUN})$ in the mice treated with IPI549, ${ }_{\mathrm{B}} \mathrm{Exo}^{\mathrm{I}}$ or ${ }_{\mathrm{G}} \mathrm{Exo}^{\mathrm{I}}$ were not significantly different from those in the healthy mice (Fig. 7b-e), indicating that this therapeutic strategy may not cause obvious damage to the liver and spleen. Moreover, no body weight loss was found in all the mice groups during the treatment process in the postoperative lung metastasis mice model (Fig. 7f). Taken all together, ${ }_{\mathrm{G}} \mathrm{Exo}^{\mathrm{I}}$ is a biocompatible choice for the suppression of metastasis.

a

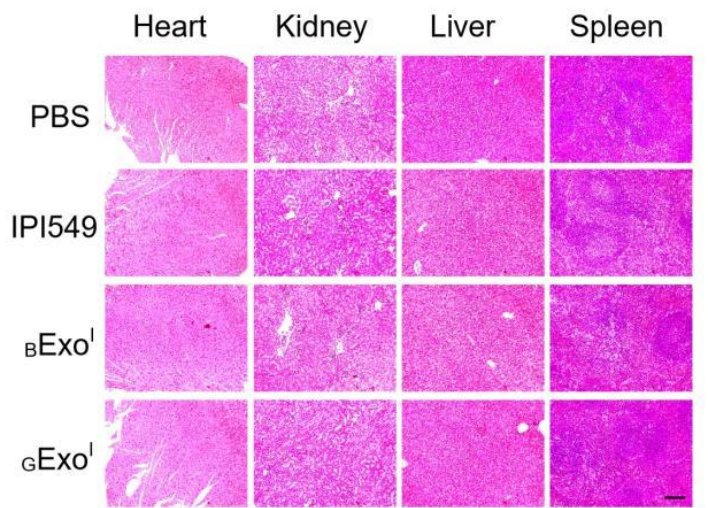

d

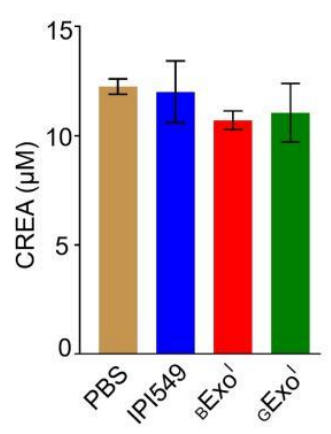

e

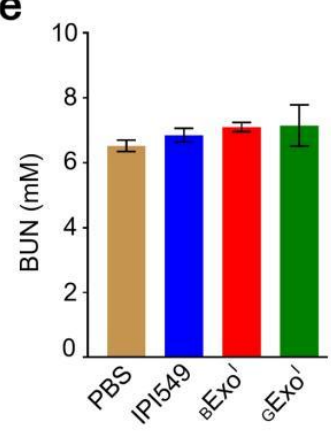

b
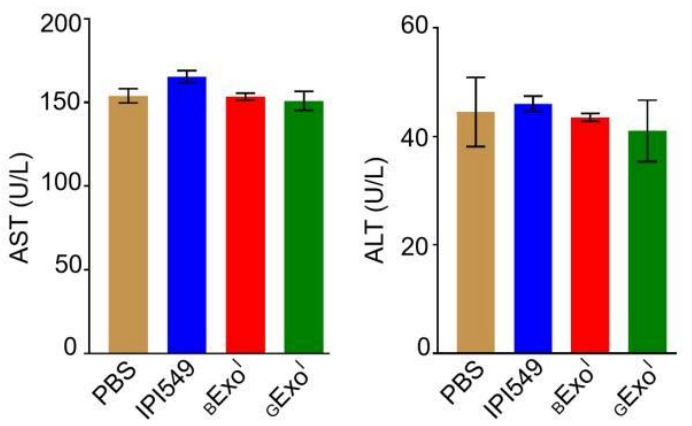

f

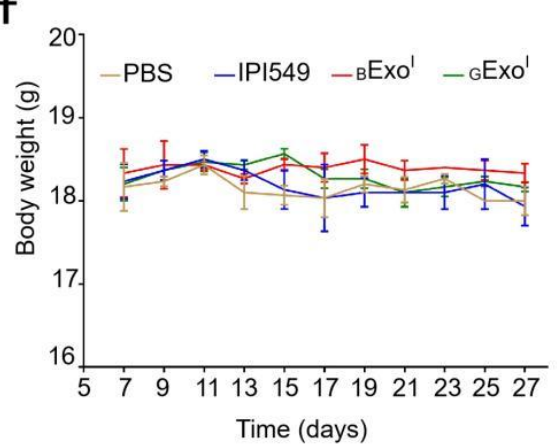

Figure 7. In vivo biocompatibility of ${ }_{\mathrm{G}} \mathbf{E x o}$. a H\&E staining of major organ sections of mice treated 
with IPI549, ${ }_{\text {B Exo }}{ }^{\mathrm{I}}$ or ${ }_{\mathrm{G}} \mathrm{Exo}^{\mathrm{I}}$. Scale bar, $200 \mu \mathrm{m}$. b-e Levels of AST b, ALT c, CREA d and BUN e in serum. f Mice body weight curves during the treatment period. Data are expressed as means \pm SD. $n=$ 5 biologically independent animals per group.

\section{Discussion}

Functional exosomes $\left({ }_{\mathrm{G}} \mathrm{Exo}^{\mathrm{I}}\right)$ were designed to suppress the lung metastasis of melanoma by preventing the PMN formation. ${ }_{\mathrm{G}} \mathrm{Exo}^{\mathrm{I}}$ that presented GFE1 peptide on the surface of exosomal membrane and loaded IPI549 inside the exosomes showed the significant targeting ability to pulmonary vascular endothelial cells and inhibit G-MDSCs accumulation in the premetastatic lung. In transwell system, ${ }_{\mathrm{G}} \mathrm{Exo}^{\mathrm{I}}$ targeting to MPVEC could release IPI549 to inhibit the migration of G-MDSCs and decrease their PI3K $\gamma$ expression. In postoperative mice model, intravenously injected ${ }_{\mathrm{G}} \mathrm{Exo}^{\mathrm{I}}$ exhibited a significant aggregation effect in the lung PMN, and transformed immunosuppressive microenvironment into immunostimulative microenvironment by decreasing the percentages of G-MDSCs, mo-MDSCs and M2 macrophage and increasing the percentages of CD4 ${ }^{+} \mathrm{T}$ cells and CD8 ${ }^{+}$ T cells, leading to the effective inhibition on tumor metastasis. Collectively, we provided herein a proof of concept that early blocking the PMN formation using organ-specific exosomes would afford a potent platform of anti-tumor organ specific metastasis.

\section{Materials and methods}

1. Isolation of primary bone marrow MSCs. Primary bone marrow MSCs were isolated from 2 or 3 week old C57BL/6 mice as previously described[39]. Briefly, bone marrow cells from the femur and tibia were flushed thoroughly with a 26-gauge syringe needle inserted into the marrow cavity. Afterwards, the diaphyses of femur and tibia were chopped into small sclerites and digested with collagenase II for $2 \mathrm{~h}$ at $37^{\circ} \mathrm{C}$ in a shaker, $100 \mathrm{rpm} \mathrm{min}-1$. During digestion, bone marrow cells were filtered using a $70 \mu \mathrm{m}$ strainer filter and centrifuged at $200 \mathrm{~g}$ for $5 \mathrm{~min}$. The cell pellet was resuspended in C57BL/6 MSC complete culture medium (Cyagen Biosciences Inc, United States) and seeded in culture dishes. After digestion, bone chips were washed 3 times with basic DMEM/F-12 and seeded 
into the culture dishes to co-culture with the bone marrow cells at $37^{\circ} \mathrm{C}$ containing $5 \% \mathrm{CO}_{2}$. After being seeded for 3 days, MSCs attached to the bottom of culture dishes and the non-adherent cells were eliminated through the exchange of the cell medium at 72 hours and every 2 days thereafter. Then the MSCs were identified by stained with anti-CD44-PE (clone IM7, Biolegend), anti-CD45-PE (clone 30-F11, Biolegend), anti-CD105-PE (clone MJ7/18, Biolegend), anti-CD34-PE (clone SA376A4, Biolegend) and anti-CD29-FITC (clone HM $\beta 1-1$, Biolegend) by flow cytometry (BD Biosciences, AccuriC6). The MSCs from passage 3 to passage 8 were implemented to extract exosomes.

2. Preparation of ${ }_{G} \mathbf{E x o}^{\mathrm{I}}$ and ${ }_{\mathbf{B}} \mathbf{E x o}^{\mathrm{I}}$. The pEGFP-C1-GFE1-Lamp2b plasmid was constructed by the Beijing Genomics institution (China). $1 \times 10^{7}$ MSCs were seeded into $100 \mathrm{~mm}$ dish. After $24 \mathrm{~h}$, the MSCs were transfected with $8 \mu \mathrm{g}$ pEGFP-C1-GFE1-Lamp2b plasmid using Lipofectamine 2000 transfection reagent (Invitrogen, USA). After 24h transfection, the transfected MSCs were washed 3 times with PBS and cultured for another $24 \mathrm{~h}$ in media with exosome-free serum containing $40 \mu \mathrm{g} \mathrm{mL}^{-1}$ IPI549. The exosomes were purified using a gradient centrifugation protocol according to the literature [51]. The cell culture supernatant containing exosomes was harvested by centrifugation at $200 \mathrm{~g}$ for 5 min to eliminate cells. The supernatant was then centrifuged at $12,000 \mathrm{~g}$ for $45 \mathrm{~min}$ to remove dead cells and cell debris. The resulting supernatant was further centrifuged at $100,000 \mathrm{~g}$ for $90 \mathrm{~min}$ (QPTimaMAX-XP Ultra-High, Beckman Coulter, USA). The pellets were washed with large volume of cold PBS and centrifuged at $120,000 \mathrm{~g}$ for 70 min again to ensure maximal exosome purity. All centrifugation procedures were performed at $4{ }^{\circ} \mathrm{C}$. The pellet of ${ }_{\mathrm{G}} \mathrm{Exo}^{\mathrm{I}}$ was resuspended in PBS and stored at $-80^{\circ} \mathrm{C}$. $\mathrm{BExo}^{\mathrm{I}}$ was prepared using the similar procedure except using the pEGFP-Lamp $2 \mathrm{~b}$ plasmid instead of the pEGFP-C1-GFE1-Lamp2b plasmid. ${ }_{\mathrm{G}}$ Exo and ${ }_{\mathrm{B}}$ Exo were prepared using the similar preparation procedure of ${ }_{\mathrm{G}} \mathrm{Exo}^{\mathrm{I}}$ and ${ }_{\mathrm{B}} \mathrm{Exo}^{\mathrm{I}}$, respectively, except without IPI549 incubation. 
3. Characterization of exosomes. The primary size and morphology of exosomes were examined using transmission electron microscope (JEM-2010) and cryo-TEM (JEOL JEM-3200FSC). Hydrodynamic size of purified exosomes was determined using Malvern Zetasizer (Nano ZS, Malvern, USA). To confirm successful isolation of exosomes from MSCs, the presence of TSG101, CD63 and CD9 on the exosome surface were measured by western blotting as mentioned by previous description [52]. The primary antibodies were shown below: anti-CD9 (Abcam, UK), anti-CD63 (Abcam, UK), anti-TSG101 (Abcam, UK). The amount of IPI549 loaded into exosomes was measured by a high performance liquid chromatography (HPLC, Waters, USA) at $254 \mathrm{~nm} .25 \mu \mathrm{g} \mathrm{BExo}^{\mathrm{I}}$ or $_{\mathrm{G}} \mathrm{Exo}^{\mathrm{I}}$ in a 1.5 $\mathrm{mL}$ centrifuge tube was heated at $75^{\circ} \mathrm{C}$ to evaporate solvent. Then, $100 \mu \mathrm{L}$ of acetonitrile was added and the mixture was vortexed, sonicated and then centrifuged at $12,000 \mathrm{rpm}$ for $10 \mathrm{~min}$. The supernatant was collected and filtered through $0.22 \mu \mathrm{m}$ microfiltration membrane. $20 \mu \mathrm{L}$ of aliquots was injected into the HPLC system. The chromatographic conditions were as follows: the column was C18 column $(4.6 \times 250 \mathrm{~mm}, 5 \mu \mathrm{m})$; the mobile phase consisted of acetonitrile: $0.1 \%$ formic acid (35:65); the column temperature was $25^{\circ} \mathrm{C}$ and the detection wavelength was $254 \mathrm{~nm}[28,53]$.

The loading capacity and encapsulation efficiency of IPI549 were calculated using the following formula, where W1 was the weight of the IPI549 enveloped in the ${ }_{\mathrm{G}} \mathrm{Exo}$, W was the weight of the exosomes, and W0 was the initial amount of IPI549 added to the culture medium.

$$
\begin{aligned}
& \mathrm{LC} \%=\frac{\mathrm{W} 1}{\mathrm{~W}} \times 100 \% \\
& \mathrm{EE} \%=\frac{\mathrm{W} 1}{\mathrm{~W} 0} \times 100 \%
\end{aligned}
$$

\section{Release assessment of IPI549 from exosomes}

$129.6 \mu \mathrm{g}{ }_{\mathrm{B}} \mathrm{Exo}^{\mathrm{I}}$ or $112.4 \mu \mathrm{g} \mathrm{G}_{\mathrm{G}} \mathrm{Exo}^{\mathrm{I}}$ (containing $20 \mu \mathrm{g}$ IPI549) suspended in $1 \mathrm{~mL}$ of PBS containing $0.5 \%$ carboxymethyl cellulose (CMC) and added to the dialysis bag with a 3500 molecular weight (Mw) 
414 cutoff. Then, the dialysis bag was immersed in a flask containing $200 \mathrm{~mL}$ of PBS and $0.5 \%$ anionic

415 surfactant sodium dodecyl sulfate (SDS) at $37^{\circ} \mathrm{C}$. Samples were taken at time points from inside the 416 flask, and the amount of released IPI549 was analyzed HPLC.

417 5. Identification of GFE1 expression on exosomes. $10 \mu \mathrm{g}$ of His-tagged recombinant DPEP1

418 (Creative BioMart, USA) was incubated with $100 \mu \mathrm{g}$ of ${ }_{\mathrm{B}} \mathrm{Exo}^{\mathrm{I}}$ or ${ }_{\mathrm{G}} \mathrm{Exo}^{\mathrm{I}}$ for $4 \mathrm{~h}$ at $4^{\circ} \mathrm{C}$. Then ${ }_{\mathrm{B}} \mathrm{Exo}^{\mathrm{I}}$ or

$419{ }_{\mathrm{G}} \mathrm{Exo}^{\mathrm{I}}$ was purified by ultracentrifugation. The expression of His-tag in ${ }_{\mathrm{B}} \mathrm{Exo}^{\mathrm{I}}$ and ${ }_{\mathrm{G}} \mathrm{Exo}^{\mathrm{I}}$ were analyzed

420 by western blot. The primary antibody was shown below: anti- $6 \times$ His-tag (Abcam, UK)

421 6. Exosome labeling. The fluorescent dye, PKH26 (Umibio, China) was used to label exosomes.

422 Purified exosomes were incubated in $5 \mathrm{mM} \mathrm{PKH} 26$ for $15 \mathrm{~min}$ at $37^{\circ} \mathrm{C}$, and then ultracentrifuged at $423120,000 \mathrm{~g}$ for $90 \mathrm{~min}$ to remove free dye. After being washed twice in PBS, the PKH26-labeled 424 exosomes were resuspended in PBS prior to use.

425 7. Cells culture. B16/F10 and RAW 264.7 cells were purchased from the American Type Culture 426 Collection (ATCC). MPVEC and MLE12 were separated from the lung of mice. All cells were cultured serum (Gibco) and 1\% penicillin/streptomycin, and maintained in $5 \% \mathrm{CO}_{2}$ at $37^{\circ} \mathrm{C}$.

\section{Animals.}

Female C57BL/6J mice (4-6-weeks-old) were purchased from the Animal Experimental Center of Jilin

431 University (Changchun, China) and kept under thermo-regulated, humidity-controlled conditions under

432 a $12 \mathrm{~h}$ day/night light cycle provided by the experimental and were fed with standard rat chow and

433 water ad libitum. All animal studies were carried out in Changchun Institute of Applied Chemistry,

434 Chinese Academy of Sciences, the operating procedures of the experimental animals were carried out 435 in accordance with protocols approved by the Committee for Animal Research of Changchun Institute 
of Applied Chemistry, Chinese Academy of Sciences China.

\section{Preparation of TCM.}

B16/F10 cells were cultured in DMEM with $10 \%$ FBS, $100 \mathrm{mg} / \mathrm{mL}$ streptomycin, and $100 \mathrm{U} / \mathrm{mL}$ penicillin at $37{ }^{\circ} \mathrm{C}$ in a humidified atmosphere containing $5 \% \mathrm{CO}_{2}$. When the cells formed a consecutive monolayer, the media was replaced with serum-free DMEM, and the cells were incubated for $24 \mathrm{~h}$. Then, the medium was collected and centrifuged. The supernatant was filtered through 0.22 $\mu \mathrm{m}$ syringe filters and stored at $-20^{\circ} \mathrm{C}$.

10. Postoperative lung metastasis mouse model. For in vivo metastasis model, B16/F10 cells $(1.0 \times$ $10^{6}$ cells) were subcutaneously injected at the back of C57BL/6 mice to establish the in situ melanoma model. When the tumor size reached $100 \mathrm{~mm}^{3}\left(\right.$ tumor volume $=\left(\right.$ length $\times$ width $\left.\left.^{2}\right) / 2\right)$, tumors were surgically excised. Seven days later, mice were intravenously injected with B16/F10 cells $\left(2.0 \times 10^{5}\right.$ cells) and the postoperative pulmonary metastasis mouse model was established.

11. Cytotoxicity assessment of exosomes. RAW264.7 cells and HUVEC in logarithmic growth phase were digested into single-cell suspensions and seeded in 96-well plates at $1 \times 10^{4}$ cells per well, and then incubated in $5 \% \mathrm{CO}_{2}$ at $37^{\circ} \mathrm{C}$ overnight. Then, the medium was replaced with $100 \mu \mathrm{L}$ of fresh medium containing various concentrations of IPI549, ${ }_{\mathrm{B}} \mathrm{Exo}^{\mathrm{I}}$ or ${ }_{\mathrm{G}} \mathrm{Exo}^{\mathrm{I}}$. After another $24 \mathrm{~h}$ of incubation, $10 \mu \mathrm{L}$ of CCK-8 reagent (CCK8, Beyotime, Shanghai, China) was added to each well and then cultured for 2 hours. The absorbance was measured at $450 \mathrm{~nm}$ by microplate reader (Bio-Rad, Hercules, CA, USA) using wells without cells as blanks.

12. In vitro Assessment of targeting ability of ${ }_{G} \mathbf{E x o}^{\mathrm{I}}$ to MPVEC. $1.5 \times 10^{5}$ MPVEC were incubated with $100 \mu \mathrm{g} \mathrm{mL}{ }^{-1}$ PKH26-labeled ${ }_{\mathrm{B}} \mathrm{Exo}^{\mathrm{I}}$ or ${ }_{\mathrm{G}} \mathrm{Exo}^{\mathrm{I}}$ for $2 \mathrm{~h}$. MLE12 cells used as control were similarly treated. The cells were washed with PBS three times and visualized by fluorescence microscopy 
(Nikon Eclipse 80i).

\section{G-MDSCs sorted from the blood and lung of tumor-bearing mice.}

To isolate G-MDSCs from blood, 2 week tumor-bearing mice were sacrificed by tail vein injection of 4\% EDTA. Blood was collected, and the erythrocytes were eliminated with hypotonic lysis buffer. The remaining cells were collected. To isolate G-MDSCs from lung, single cell suspensions of lungs were prepared by cutting the organs into small fragments, digesting them at $37^{\circ} \mathrm{C}$ for 1 hour with $1 \mathrm{mg} \mathrm{mL}^{-1}$ collagenase I and then filtering them through a $70 \mu \mathrm{m}$ cell strainer. Erythrocytes were lysed with Red Blood Cell Lysis Buffer (Beyotime, China). The G-MDSCs were sorted with a Myeloid-Derived Suppressor Cell Isolation Kit using an AutoMACS sorter (Miltenyi Biotec, Germany) according to the manufacturer's instructions. $1 \times 10^{8}$ cells from blood or lungs were centrifuged at $300 \mathrm{~g}$ for $10 \mathrm{~min}$ at $4^{\circ} \mathrm{C}$. The cell pellets were resuspended in $700 \mu \mathrm{L}$ of PBS (pH 7.2), $0.5 \%$ bovine serum albumin, and 2 mM EDTA. Fetal bovine serum $(50 \mu \mathrm{L})$ was added, mixed well, and incubated for $10 \mathrm{~min}$ at $4^{\circ} \mathrm{C}$. After incubation, $100 \mu \mathrm{L}$ of biotin-conjugated anti-Ly6G antibody was added and the cells incubated for a further $15 \mathrm{~min}$ at $4^{\circ} \mathrm{C}$. Cells were washed by adding $10 \mathrm{~mL}$ of buffer and centrifuging at $300 \mathrm{~g}$ for 10 $\min$ at $4^{\circ} \mathrm{C}$. The labeled cells were resuspended in $800 \mu \mathrm{L}$ of buffer; then, $200 \mu \mathrm{L}$ of anti-biotin microbeads was added, mixed well, and incubated for $10 \mathrm{~min}$ at $4^{\circ} \mathrm{C}$. Cells were washed by adding 10 $\mathrm{mL}$ of buffer and centrifuging at $300 \mathrm{~g}$ for $10 \mathrm{~min}$ at $4^{\circ} \mathrm{C}$. The cell pellets were then resuspended in 500 $\mu \mathrm{L}$ of buffer. Then, the cell suspension was loaded onto a MACS column, which was placed in the magnetic field of a MACS Separator. The magnetically labelled G-MDSCs cells were retained in the column and washed from the column.

14. The inhibition of ${ }_{G} \mathbf{E x o}^{\mathrm{I}}$ on G-MDSCs chemotactic migration in vitro. $5.0 \times 10^{4}$ G-MDSCs sorted from the blood of tumor-bearing mice were seeded onto transwell inserts with a polyethylene 
terephthalate membrane pore size of $5 \mu \mathrm{m}$ (Corning) in 24-well plates, while CXCL1 $\left(10 \mathrm{ng} \mathrm{mL}^{-1}\right.$ PeproTech Co., Ltd., USA) was added into the lower chamber. Then, $50 \mu \mathrm{g} \mathrm{mL}^{-1}{ }_{\mathrm{B}} \mathrm{Exo},{ }_{\mathrm{G}} \mathrm{Exo},{ }_{\mathrm{B}} \mathrm{Exo}^{\mathrm{I}}$ or ${ }_{\mathrm{G}} \mathrm{Exo}^{\mathrm{I}}$ were added to the upper chamber for $4 \mathrm{~h}$. Then the number of G-MDSCs migrated into the lower chamber was counted by flow cytometry (BD Biosciences, AccuriC6). To further evaluate the inhibitory effect of ${ }_{\mathrm{G}} \mathrm{Exo}^{\mathrm{I}}$ targeting MPVEC on G-MDSC migration, MPVEC were first incubated with $100 \mu \mathrm{g} \mathrm{mL}{ }^{-1}{ }_{\mathrm{G}} \mathrm{Exo}^{\mathrm{I}}$ or ${ }_{\mathrm{B}} \mathrm{Exo}^{\mathrm{I}}$ for $2 \mathrm{~h}$, and then the cells were collected and washed with PBS for 3 times to remove unbound exosomes. $1.0 \times 10^{5}$ G-MDSCs and $1.0 \times 10^{5}$ these exosome-treated MPVEC were cultured in the upper chamber while CXCL1 $\left(10 \mathrm{ng} \mathrm{mL}^{-1}\right)$ in the lower chamber for $4 \mathrm{~h}$. Then the number of G-MDSCs migrated into the lower chamber was counted by flow cytometry. The percentage of migrated G-MDSCs = the number of migrated G-MDSCs/ the total number of G-MDSCs.

15. Inhibitory effect of exosomes on PI3K $\gamma$ expression in G-MDSCs. G-MDSCs in the upper chamber of transwell system were harvested or G-MDSCs in the lung of postoperative lung metastasis mice treated with PBS, IPI549, ${ }_{\mathrm{B}} \mathrm{Exo}^{\mathrm{I}}$ or ${ }_{\mathrm{G}} \mathrm{Exo}^{\mathrm{I}}$ through intravenously injection were sorted. Then the G-MDSCs were washed with PBS, and mixed with $50 \mu \mathrm{L}$ cell lysate buffer (Beyotime, China). Samples were centrifuged at $4{ }^{\circ} \mathrm{C}$ and $12,000 \mathrm{rpm}, 30 \mathrm{~min}$, and the supernatant was collected for Western blot assay. The proteins of the collected supernatant were separated by sodium dodecyl sulfate-polyacryl amidegel electrophoresis (SDS-PAGE) and transferred onto nitrocellulose blotting membranes (GE Healthcare Life Science, Boston, Massachusetts). Anti-PI3K $\gamma$ (1:1000, Santa Cruz Biotechnology, USA) was incubated with the membrane overnight at $4^{\circ} \mathrm{C}$. Horseradish peroxidase-conjugated goat anti-mouse or goat anti-rabbit IgG secondary antibody (1:1000, Beyotime, China) was incubated with the membranes for $1 \mathrm{~h}$ at room temperature. The proteins on the membranes were detected using a Tanon imaging system (5200, Shanghai, China). 
16. Pharmacokinetics and distribution of exosomes. The tissue distribution and bioavailability of free IPI549, ${ }_{\mathrm{B}} \mathrm{Exo}^{\mathrm{I}}$ and ${ }_{\mathrm{G}} \mathrm{Exo}^{\mathrm{I}}$ in mice were detected as following method [54]. Briefly, healthy C57BL/6 mice were randomly divided into three groups, namely, free IPI549, ${ }_{\mathrm{B}} \mathrm{Exo}^{\mathrm{I}}$ and ${ }_{\mathrm{G}} \mathrm{Exo}^{\mathrm{I}}$, weighed and intravenously injected with a single dose of various formulations at $0.2 \mathrm{mg} \mathrm{kg}^{-1}$ equivalent to the content of IPI549. Blood samples were periodically collected via eye sinus bleeding and immediately centrifuged to obtain plasma for determining IPI549 content at different time point by HPLC. At $24 \mathrm{~h}$ after dosing, all the animals were euthanized and their tissues (liver, kidney, lung) were immediately dissected out and homogenized to extract the IPI549 for HPLC analysis. To further monitor the distribution of ${ }_{\mathrm{B}} \mathrm{Exo}^{\mathrm{I}}$ and ${ }_{\mathrm{G}} \mathrm{Exo}^{\mathrm{I}}$ in mice, the $\mathrm{C} 57 \mathrm{BL} / 6$ mice were randomly divided into three groups,

PBS, PKH26-labeled ${ }_{\mathrm{B}} \mathrm{Exo}^{\mathrm{I}}$ and $\mathrm{PKH} 26$-labeled ${ }_{\mathrm{G}} \mathrm{Exo}^{\mathrm{I}}$, weighed and intravenously administered a single dose of various formulations at $0.2 \mathrm{mg} / \mathrm{kg}$ equivalent to the content of IPI549. After $24 \mathrm{~h}$, the hearts, livers, spleens, lung and kidneys of the mice were dissected, and a fluorescence imaging system (Davinch-Invivo) was employed to capture the PKH26 fluorescence images of the organs.

\section{In vivo targeting ability assessment}

PKH26-labeled ${ }_{\mathrm{B}} \mathrm{Exo}^{\mathrm{I}}$ or ${ }_{\mathrm{G}} \mathrm{Exo}^{\mathrm{I}}$ were intravenously injected into healthy $\mathrm{C} 57 \mathrm{BL} / 6$ mice $(0.2 \mathrm{mg}$ of IPI549-equiv per kg of body weight), and the treated mice were sacrificed after $24 \mathrm{~h}$. Lung tissues were collected and embedded in opti-mum cutting temperature compound (Sakura; Torrance, CA). The frozen sections were fixed with acetone, incubated with $2 \mu \mathrm{g} \mathrm{mL}^{-1}$ anti-mouse CD31 antibody (Abcam, UK) overnight at $4^{\circ} \mathrm{C}$, and then stained with FITC rabbit anti-goat $\operatorname{IgG}(\mathrm{H}+\mathrm{L})(1: 500$ dilution, ABclonal) for $1 \mathrm{~h}$ at room temperature. The fluorescent signals of section were detected under fluorescence microscopy. 
$\mu \mathrm{L}$ ) was intravenously injected into C57BL/6 mice one time per day for 3 days. After each TCM injection on the same day, the mice were intravenously injected with IPI549, ${ }_{\mathrm{B}} \mathrm{Exo}^{\mathrm{I}}$ and ${ }_{\mathrm{G}} \mathrm{Exo}^{\mathrm{I}}(0.2 \mathrm{mg}$ $\mathrm{kg}^{-1}$ equivalent to the content of IP549). Then, B16/F10 cells $\left(2.0 \times 10^{5}\right.$ cells $)$ were intravenously injected after 3 days. The lungs were harvested after 14 days of B16/F10 cells intravenous injection and the number of macroscopic metastatic nodules in the lung was recorded.

\section{In vivo efficacy of ${ }_{\mathrm{G}} \mathrm{Exo}^{\mathrm{I}}$ preventing $\mathrm{PMN}$ formation and against pulmonary metastases}

Female C57BL/6 mice with established postoperative lung metastasis were randomly divided into 4

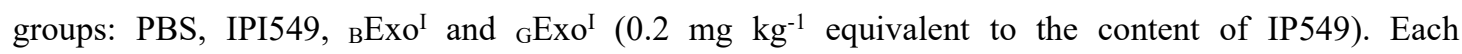
intravenous injection was administered every other day (total for 6 doses) through the tail vein. The first treatment was 2 days after the establishment of the postoperative lung metastasis model. Two days after the last injection, animals were sacrificed to harvest lungs, and the number of macroscopic metastatic nodules in each lung was recorded to evaluate the therapeutic effects. Furthermore, single cell suspensions of a piece of the lungs were prepared as described above to detect the percentage of G-MDSCs and mo-MDSCs through staining with anti-CD11b-FITC (clone M1/70, BD), anti-CD45-PE/Cy7 (clone 30-F11, BD), anti-Ly6G-APC/Cy7 (clone 1A8, BD) and anti-Ly6C-PE (clone AL-21, BD), respectively, to detect the percentage of $\mathrm{CD}^{+} \mathrm{T}$ cells and $\mathrm{CD} 8^{+} \mathrm{T}$ cells through staining with anti-CD3-FITC (clone 17A2, Biolegend), anti-CD4-PE (clone GK1.5, Biolegend) and anti-CD8-APC (clone 53-6.7, Biolegend), respectively, and to detect the percentage of M2 phenotype macrophages through staining with anti-F4/80-FITC (clone BM8, Biolegend) and anti-CD206-APC 

slices were performed with H\&E staining for visualization of metastatic foci.

\section{Toxicity Evaluation in Vivo.}

The body weight of each mouse was measured every 2 day from tumors excised. At the end of systematic administration, major organs (heart, liver, spleen, and kidney) were harvested as mentioned above and served for H\&E staining and aspartate transaminase (AST), alanine transaminase (ALT), creatinine (CREA) and blood urea nitrogen (BUN) levels of serum collecting from different treated mice were detected using a commercial kit (Nanjing Institute of Biological Engineering, Nanjing, China) according to the manufacturer's protocol.

21. Statistical analysis. All data analyses were performed using GraphPad Prism 6.0 (GraphPad Software, La Jolla, CA, USA). Data are presented as the mean \pm SD. Student's t-test was used to analyze differences between two groups. One-way ANOVA was used to perform the multi-sample analysis followed by the Tukey post hoc test. Differences at $\mathrm{P}<0.05$ were considered statistically significant .

Author contributions

Conceptualization, methodology, investigation: Xiaoqing Han; investigation, manuscript revision: 
The authors declare no competing financial interest.

Acknowledgements

This work was primarily supported by the National Natural Science Foundation of China (22007087 and 22077119).

References

1. Bray, F., et al. Global cancer statistics 2018: GLOBOCAN estimates of incidence and mortality worldwide for 36 cancers in 185 countries. CA. Cancer J Clin. 68, 394-424 (2018).

2. Fidler, I.J. The pathogenesis of cancer metastasis: the 'seed and soil' hypothesis revisited. Nature Reviews Cancer. 3, 453-458 (2003). 3. Wan, L., K. Pantel, \& Kang, Y. Tumor metastasis: moving new biological insights into the clinic. Nat. Med. 19, 1450-1464 (2013). 4. Chambers, A.F., Groom, A.C. \& MacDonald, I.C. Dissemination and growth of cancer cells in metastatic sites. Nat. Rev. Cancer. 2, 563-572 (2002).

7. Li, W., Yu Y., Wang, H., Yan, A. \& Jiang, X. Evaluation of the prognostic impact of postoperative adjuvant radiotherapy on head and neck mucosal melanoma: a meta-analysis. BMC. Cancer. 15, 758

(2015)

588 8. Langley, R.R. \& Fidler, I.J. Tumor cell-organ microenvironment interactions in the pathogenesis of cancer metastasis. Endocr. Rev. 28, 297-321 (2007).

9. Kaplan, R.N., et al. VEGFR1-positive haematopoietic bone marrow progenitors initiate the 591 pre-metastatic niche. Nature. 438, 820-827 (2005).

592 10. Liu, Y. \& Cao, X. Characteristics and Significance of the Pre-metastatic Niche. Cancer Cell. 30, $593 \quad 668-681(2016)$.

594 11. Quail, D.F. \& Joyce, J.A. Microenvironmental regulation of tumor progression and metastasis. Nature Medicine. 19, 1423-1437 (2013). 

and Metastasis Reviews. 32, 449-464 (2013).

13. Peinado, H., et al. Pre-metastatic niches: organ-specific homes for metastases. Nat. Rev. Cancer. 17, 302-317 (2017).

14. Jiang, T., et al. Metformin and Docosahexaenoic Acid Hybrid Micelles for Premetastatic Niche Modulation and Tumor Metastasis Suppression. Nano Lett. 19, 3548-3562 (2019).

15. Long, Y., et al. Self-Delivery Micellar Nanoparticles Prevent PremetSSastatic Niche Formation by Interfering with the Early Recruitment and Vascular Destruction of Granulocytic Myeloid-Derived Suppressor Cells. Nano Lett. 20, 2219-2229 (2020).

16. Sceneay, J., et al. Primary tumor hypoxia recruits CD11b+/Ly6Cmed/Ly6G+ immune suppressor cells and compromises NK cell cytotoxicity in the premetastatic niche. Cancer Res. 72, 3906-3911 (2012).

17. Wang, Y., Ding, Y., Guo, N., \& Wang, S., et al., MDSCs: Key Criminals of Tumor Pre-metastatic Niche Formation. Front Immunol. 10, 172-188 (2019).

18. Kowanetz, M., et al. Granulocyte-colony stimulating factor promotes lung metastasis through mobilization of Ly6G+Ly6C+ granulocytes. Proc. Natl. Acad. Sci. USA. 107, 21248-21255 (2010).

19. Kitamura, T., Qian,B.-Z. \& Pollard, J.W. Immune cell promotion of metastasis. Nat. Rev. Immunol. $15,73-86(2015)$.

20. Engblom, C., Pfirschke,C. \& Pittet, M.J. The role of myeloid cells in cancer therapies. Nat. Rev. Cancer. 16, 447-462 (2016).

21. Yan, H.H., et al. Gr-1+CD11b+ myeloid cells tip the balance of immune protection to tumor promotion in the premetastatic lung. Cancer Res. 70, 6139-6149 (2010).

22. Ouzounova, M., et al. Monocytic and granulocytic myeloid derived suppressor cells differentially regulate spatiotemporal tumour plasticity during metastatic cascade. Nat. Commun. 8, 14979-14992 (2017).

23. Kumar, V., Patel, S., Tcyganov, E. \& Gabrilovich, D. The Nature of Myeloid-Derived Suppressor Cells in the Tumor Microenvironment. Trends immunol. 37, 208-220 (2016).

24. Zhou, Y. \& Guo, F. A selective sphingosine-1-phosphate receptor 1 agonist SEW-2871 aggravates gastric cancer by recruiting myeloid-derived suppressor cells. J. Biochem. 163, 77-83 (2018).

25. Cheng, Y., et al. Potential roles and targeted therapy of the CXCLs/CXCR2 axis in cancer and 
inflammatory diseases. Biochim. Biophys. Acta Rev. Cancer. 1871, 289-312 (2019).

26. Wang, D., Sun, H., Wei, J., Cen, B., \& DuBois, R. CXCL1 Is Critical for Premetastatic Niche Formation and Metastasis in Colorectal Cancer. Cancer Res. 77, 3655-3665 (2017).

27. Ferguson, G.J., et al. PI(3)Kgamma has an important context-dependent role in neutrophil chemokinesis. Nat. Cell Biol. 9, 86-91 (2007).

28. Gao, Y., et al. Metastasis Organotropism: Redefining the Congenial Soil. Dev. Cell. 49, 375-391 (2019).

29. Creasy, J.M., et al. Actual 10-year survival after hepatic resection of colorectal liver metastases: what factors preclude cure? Surgery. 163, 1238-1244 (2018).

30. Parker, C., et al. Alpha emitter radium-223 and survival in metastatic prostate cancer. N. Engl. J. Med. 369, 213-223 (2013).

31. Pegtel, D.M. \& Gould, S.J. Exosomes. Annu. Rev. Biochem. 88, 487-514 (2019).

32. Tian, Y., et al. A doxorubicin delivery platform using engineered natural membrane vesicle exosomes for targeted tumor therapy. Biomaterials. 35, 2383-2390 (2014).

33. Tian, R., et al. Tumor Exosome Mimicking Nanoparticles for Tumor Combinatorial Chemo-Photothermal Therapy. Front Bioeng Biotechnol. 8, 1010-1021 (2020).

34. Bunggulawa, E.J., et al., Recent advancements in the use of exosomes as drug delivery systems. $J$. Nanobiotechnology. 16, 81-81 (2018).

35. Xiong, F., et al. Pursuing Specific Chemotherapy of Orthotopic Breast Cancer with Lung Metastasis from Docking Nanoparticles Driven by Bioinspired Exosomes. Nano Lett. 19, 3256-3266 (2019).

36. Zhao, L., et al. Exosome-mediated siRNA delivery to suppress postoperative breast cancer metastasis. J. Control Release. 318, 1-15 (2020).

37.Lv, Q., et al. Thermosensitive Exosome-Liposome Hybrid Nanoparticle-Mediated Chemoimmunotherapy for Improved Treatment of Metastatic Peritoneal Cancer. Adv. Sci (Weinh). 7, 2000515 (2020).

38. Alvarez-Erviti, L., et al. Delivery of siRNA to the mouse brain by systemic injection of targeted exosomes. Nat. Biotechnol. 29, 341-345 (2011).

39. Wang, X., et al. Engineered Exosomes With Ischemic Myocardium-Targeting Peptide for Targeted Therapy in Myocardial Infarction. J. Am. Heart Assoc. 7, e008737 (2018). 
40. Zhuang, M., et al. SPION decorated exosome delivery of TNF-alpha to cancer cell membranes through magnetism. Nanoscale. 12, 173-188 (2020).

41. Smyth, T., et al. Surface functionalization of exosomes using click chemistry. Bioconjug Chem. 25, $1777-1784$ (2014).

42. Yeo, R.W., et al. Mesenchymal stem cell: an efficient mass producer of exosomes for drug delivery. Adv. Drug Deliv. Rev. 65, 336-341 (2013).

43. Rajotte, D. \& Ruoslahti, E. Membrane dipeptidase is the receptor for a lung-targeting peptide identified by in vivo phage display. J. Biol. Chem. 274, 11593-11598 (1999).

44. Rajotte, D., et al. Molecular heterogeneity of the vascular endothelium revealed by in vivo phage display. J. Clin. Invest. 102, 430-437 (1998).

45. Wu, C.F., et al. The lack of type I interferon induces neutrophil-mediated pre-metastatic niche formation in the mouse lung. Int. J. Cancer. 137, 837-847 (2015).

46. Highfill, S.L., et al. Disruption of CXCR2-Mediated MDSC Tumor Trafficking Enhances Anti-PD1 Efficacy. Sci. Transl. Med. 6, 237 ra67 (2014).

47. Shi, H., et al. Chemokine (C-X-C motif) ligand 1 and CXCL2 produced by tumor promote the generation of monocytic myeloid-derived suppressor cells. Cancer Sci. 109, 3826-3839 (2018).

48. Sinha, P., Clements, V., Bunt, S., Albelda, S.\& Ostrand-Rosenberg, S. Cross-Talk between Myeloid-Derived Suppressor Cells and Macrophages Subverts Tumor Immunity toward a Type 2 Response. J. Immunol. 179, 977-983 (2007).

49. Kak, G., M. Raza, \& Tiwari, B.K. Interferon-gamma (IFN-gamma): Exploring its implications in infectious diseases. Biomol Concepts. 9, 64-79 (2018).

50. Hamidullah, Changkija, B.\& Konwar, R. Role of interleukin-10 in breast cancer. Breast Cancer Res. Treat. 133, 11-21 (2012).

51. Yuan, D., et al. Macrophage exosomes as natural nanocarriers for protein delivery to inflamed brain. Biomaterials. 142, 1-12 (2017).

52. $\mathrm{Su}, \mathrm{D}$., et al. Exosomal PD-L1 functions as an immunosuppressant to promote wound healing. $J$. Extracell. Vesicles. 9, 1709262-1709262 (2019).

53. Zhang, X., Shen, L., Liu, Q., Hou, L. \& Huang, L. Inhibiting PI3 kinase-gamma in both myeloid and plasma cells remodels the suppressive tumor microenvironment in desmoplastic tumors. J. Control Release. 309, 173-180 (2019). 
686 54. Wang, H., et al. Curcumin-primed exosomes potently ameliorate cognitive function in AD mice by 687 inhibiting hyperphosphorylation of the Tau protein through the AKT/GSK-3beta pathway. Nanoscale. 688 11, 7481-7496(2019). 


\section{Supplementary Files}

This is a list of supplementary files associated with this preprint. Click to download.

- supplementaryinformation.pdf 